\title{
Review
}

\section{Blood Pressure Reduction and Cardiovascular Prevention: An Update Including the 2003-2004 Secondary Prevention Trials}

\author{
Jan A. STAESSEN, Yan LI*, Lutgarde THIJS, and Ji-Guang WANG*
}

\begin{abstract}
In a meta-analysis published in June 2003, we reported that new and old classes of antihypertensive drugs had similar long-term efficacy and safety. Furthermore, we observed that in clinical trials in hypertensive or high-risk patients gradients in systolic blood pressure (SBP) accounted for most differences in outcome. To test whether our previous conclusions would hold, we updated our quantitative overview with new information from clinical trials published before 2005. To compare new and old antihypertensive drugs, we computed pooled odds ratios from stratified $2 \times 2$ contingency tables. In a meta-regression analysis, we correlated these odds ratios with corresponding between-group differences in SBP. We then contrasted observed odds ratios with those predicted from gradients in SBP. The main finding of our overview was that reduction in SBP largely explained cardiovascular outcomes in the recently published actively controlled trials in hypertensive patients and in placebo-controlled secondary prevention trials. The published results suggested that dihydropyridine calcium-channel blockers might offer a selective benefit in the prevention of stroke and inhibitors of the renin-angiotensin system in the prevention of heart failure. For prevention of myocardial infarction, the published results were more equivocal, because of the benefit of amlodipine over placebo or valsartan in 2 trials, whereas other placebo-controlled trials of calcium-channel blockers or angiotensin converting enzyme inhibitors did not substantiate the expected benefit with regard to cardiac outcomes. In conclusion, the hypothesis that new antihypertensive drugs might influence cardiovascular prognosis over and beyond their antihypertensive effect remains unproven. Our overview emphasizes the need of tight blood pressure control, but does not allow determining to what extent blood pressure must be lowered for optimal cardiovascular prevention. (Hypertens Res 2005; 28: 385-407)
\end{abstract}

Key Words: blood pressure, clinical trial, heart failure, myocardial infarction, stroke

\section{Introduction}

Hypertension affects from $20 \%$ to $30 \%$ of the world's population and is a major cardiovascular risk factor $(1,2)$. The relation between cardiovascular risk and blood pressure is continuous, consistent across age groups, present in all ethnic groups, and independent of other risk factors $(1,2)$. The ultimate goal of any blood pressure-lowering therapy is to reverse the risk associated with an elevated blood pressure and to prevent the cardiovascular complications associated with hypertension $(3,4)$.

From the Study Coordinating Centre, Hypertension and Cardiovascular Rehabilitation Unit, Department of Molecular and Cardiovascular Research, University of Leuven, Leuven, Belgium; and *the Centre for Epidemiological Research and Clinical Trials, Shanghai Institute of Hypertension, Shanghai Second Medical University, Shanghai, P.R. China.

The fellowships of Y.L. and J.-G.W. were funded as part of a bilateral scientific collaboration between the People's Republic of China and Flanders, Ministry of the Flemish Community, Brussels, Belgium (BIL 02/10).

Address for Reprints: Jan A. Staessen, M.D., Ph.D., Studiecoördinatiecentrum, Laboratorium Hypertensie, Campus Gasthuisberg, Onderwijs en Navorsing, Herestraat 49, bus 702, B-3000 Leuven, Belgium. E-mail: jan.staessen@med.kuleuven.be

Received January 31, 2005; Accepted in revised form March 22, 2005. 
Placebo-controlled clinical trials have proven that blood pressure lowering with various drug classes, including diuretics, $\beta$-blockers, calcium-channel blockers, angiotensin converting-enzyme (ACE) inhibitors and angiotensin II type 1 receptors (AR1) blockers, reduces the incidence of cardiovascular complications. Over the past decade, clinical trials of blood pressure-lowering drugs shifted focus from placebocontrolled to actively controlled designs in hypertensive patients and from primary to secondary prevention in highrisk patients with or without hypertension. The research goal underlying many of the more recent trials was to prove that the new classes of antihypertensive drugs provide superior protection against cardiovascular complications, especially in patients with a previous history of cardiovascular disease, such as coronary heart disease or stroke. The aim of the present review was to summarize the main results of these studies in light of the overall evidence from clinical trials in hypertension and to investigate to what extent blood pressurelowering rather than specific ancillary properties might have contributed to the observed outcomes.

\section{New vs. Old Antihypertensive Drugs}

In consecutive quantitative overviews of the actively controlled outcome trials (5-7), we computed pooled estimates for the comparison of new antihypertensive drugs, such as calcium-channel blockers, ACE inhibitors, AR1 blockers and $\alpha$-blockers, with conventional therapy consisting of diuretics and/or $\beta$-blockers. In 2003 (7), we reviewed 18 reports on 15 trials (8-25), in which 120,574 patients had been randomized. Table 1 summarizes the characteristics of the trials comparing new antihypertensive drugs with conventional therapy, which were published in 2002 or later.

To compare new and old antihypertensive drugs, we computed pooled odds ratios from stratified $2 \times 2$ contingency tables. If Zelen's test of heterogeneity was significant, we used a random effects model.

\section{Calcium-Channel Blockers vs. Conventional Therapy}

For the comparison of calcium-channel blockers with conventional therapy, our last review (7) considered 9 trials $(8$, $10-13,19-21,26$ ) with 67,435 randomized patients. These trials were ALLHAT/Aml (21), CONVINCE (19), ELSA (20, 22), INSIGHT (12), MIDAS (8), NICS (10), NORDIL (13), STOP2/CCBs (11), and VHAS (26). None of the outcomes considered in these analyses, including total and cardiovascular mortality, all cardiovascular events (Fig. 1), stroke (Fig. 2), myocardial infarction (Fig. 3) or heart failure, showed a statistically significant level of heterogeneity among the trials (7).

The pooled odds ratios expressing the possible benefit of calcium-channel blockers over old drugs were close to unity and non-significant for total mortality $(0.98 ; 95 \%$ confidence interval CI, 0.92-1.03; $p=0.42$ ), cardiovascular mortality (1.03; CI, 0.95-1.11; $p=0.51)$, all cardiovascular events (1.03; CI, 0.99-1.08; $p=0.15)$ and myocardial infarction (1.02; CI, 0.95-1.10; $p=0.61)$. Calcium-channel blockers provided slightly better protection against fatal and non-fatal stroke than old drugs (Fig. 2). For the 9 trials combined ( 8 , $10-12,20,21,26-28)$, the pooled odds ratio for stroke was 0.92 (CI, 0.84-1.01; $p=0.07$ ). After exclusion of CONVINCE (28), a large trial based on verapamil, the odds ratio for stroke was 0.90 and reached significance (CI, 0.82-0.98; $p=0.02$ ). For heart failure, calcium-channel blockers provided less protection than conventional therapy, regardless of whether $(1.33$; CI, $1.22-1.44 ; p<0.0001)$ or not $(1.33$; CI, $1.22-1.46 ; p<0.0001)$ we incorporated the CONVINCE trial (28) in the pooled estimates.

A re-run of the analysis in December 2004 with coronary heart disease and stroke as the outcomes of interest confirmed the above results (7). In addition to the 9 trials $(8,10-12,20$, $21,26-28)$ previously reviewed, we also included INVEST (29) and SHELL (30), but not AASK, because the published information on cause-specific cardiovascular complications was not sufficiently detailed (31). The $p$-values for heterogeneity remained non-significant. Pooled estimates were 1.02 (CI, 0.96-1.09; $p=0.55$ ) and 0.92 (CI, 0.85-0.99; $p=0.03$ ) for coronary heart disease and stroke, respectively. After exclusion of the 2 verapamil-based trials $(28,29)$, the common odds ratio for stroke was 0.90 (CI, 0.82-0.98; $p=0.02$ ).

\section{ACE Inhibitors vs. Conventional Therapy}

Our 2003 review (7) considered 6 trials $(9,11,16,21,23,25)$ that compared ACE inhibitors with old drugs and that had a combined total of 47,519 randomized patients. These trials included: ALLHAT/Lis (21), ANBP2 (23), CAPPP (9), HYVET/AD (25), STOP2/ACEIs (11), and UKPDS/CA (16). For total and cardiovascular mortality, stroke (Fig. 2) and myocardial infarction (Fig. 3), p-values indicating heterogeneity among these trials were non-significant. In contrast, for all cardiovascular events (Fig. 1) and heart failure, heterogeneity was significant due to the ALLHAT findings (21). Compared to those treated with chlorthalidone (21), the ALLHAT patients given lisinopril had greater risks of stroke (1.15; CI, $1.02-1.30 ; p=0.02)$, heart failure (1.19; CI, 1.07-1.31; $p<0.001)$, and hence combined cardiovascular disease (1.10; CI, 1.05-1.16; $p<0.001)$.

The pooled odds ratios expressing the possible benefit of ACE inhibitors over conventional therapy were close to unity and non-significant for total mortality (1.00; CI, 0.94-1.06; $p=0.89)$, cardiovascular mortality (1.02; CI, 0.94-1.11; $p=0.61$ ), all cardiovascular events (1.03; CI, 0.94-1.12; $p=0.59)$, myocardial infarction (0.97; CI, 0.90-1.04; $p=0.39$ ), and heart failure (1.04; CI, 0.89-1.22; $p=0.64)$. Compared to old drugs, ACE inhibitors gave slightly less protection against stroke with a pooled odds ratio of 1.10 (CI, $1.01-1.20 ; p=0.03)$. A further review of the literature in 
Table 1. Trials of New vs. Old Drug Classes Published in 2002-2004

\begin{tabular}{|c|c|c|c|c|c|c|c|c|c|}
\hline & ALLHAT/Aml & ALLHAT/Lis & ANBP2 & CONVINCE & ELSA & HYVET/AD & INVEST & SCOPE & SHELL \\
\hline Reference(s) & $(21)$ & $(21)$ & (23) & (19) & $(20,22)$ & $(25)$ & (29) & $(24,109)$ & (30) \\
\hline Degree of blinding & Double & Double & PROBE & Double & Double & PROBE & PROBE & Double & PROBE \\
\hline Number of patients & 24,303 & 24,309 & 6,083 & 16,476 & 2,334 & 857 & 22,576 & 4,937 & 1,882 \\
\hline Reference (old drugs) & 15,255 & 15,255 & 3,039 & 8,297 & 1,157 & 426 & 11,267 & 2,460 & 940 \\
\hline Experimental (new drugs) & 9,048 & 9,054 & 3,044 & 8,179 & 1,177 & 431 & 11,309 & 2,477 & 942 \\
\hline \multicolumn{10}{|l|}{ Treatment } \\
\hline Old drug(s) & $\begin{array}{c}\text { Chlorthali- } \\
\text { done }\end{array}$ & $\begin{array}{c}\text { Chlorthali- } \\
\text { done }\end{array}$ & Diuretics & $\begin{array}{c}\text { Atenolol or } \\
\text { HCTZ }\end{array}$ & Atenolol & $\begin{array}{c}\text { BFMT or } \\
\text { other thiazide }\end{array}$ & Atenolol & $\begin{array}{l}\text { Placebo plus } \\
\text { AH drugs }\end{array}$ & $\begin{array}{c}\text { Chlorthali- } \\
\text { done }\end{array}$ \\
\hline New drug(s) & Amlodipine & Lisinopril & ACEIs & $\begin{array}{l}\text { COER-vera- } \\
\text { pamil }\end{array}$ & Lacidipine & ACEIs & Verapamil & Candesartan & Lacidipine \\
\hline Primary endpoint & $\mathrm{CM}+\mathrm{MI}$ & $\mathrm{CM}+\mathrm{MI}$ & $\mathrm{ACM}+\mathrm{CVE}$ & $\mathrm{CVM}+\mathrm{S}+\mathrm{MI} \mathrm{H}$ & Rate of CIMT & T $\mathrm{ACM}+\mathrm{S}$ & $\mathrm{ACM}+\mathrm{S}+\mathrm{MI}$ & $\mathrm{CVM}+\mathrm{MI}+\mathrm{S}$ & CVE \\
\hline Mean age (years) & 66.9 & 66.9 & 72.0 & 65.6 & 56.0 & 83.8 & 52.1 & 76.4 & 72.3 \\
\hline \multicolumn{10}{|l|}{ Mean systolic/diastolic BP (mmHg) } \\
\hline At randomization & $146 / 84^{*}$ & $146 / 84^{*}$ & $167 / 91$ & $150 / 87^{*}$ & $164 / 101$ & $181 / 100$ & $151 / 87^{*}$ & $166 / 90^{*}$ & $178 / 87$ \\
\hline Difference during follow-up ${ }^{\dagger}$ & $-1.1^{\ddagger} /+0.6^{\ddagger}$ & $-2.3 \$ /+0.2$ & $-1.4 / \sim 0$ & $+0.1 /+0.7$ & $+0.6 /+0.2$ & $+1.4 / \sim 0$ & $-0.2 /-0.3$ & $+3.2^{\ddagger} /+1.6^{\ddagger}$ & $+1.7 /-0.3$ \\
\hline Mean serum creatinine $(\mu \mathrm{mol} / \mathrm{l})$ & 78 & 78 & - & - & 84 & 102 & - & 88 & - \\
\hline \multicolumn{10}{|l|}{ Proportion of patients ( $\%)$} \\
\hline Women & 47.1 & 46.7 & 49.0 & 55.4 & 45.2 & 63.5 & 52.1 & 64.5 & 61.3 \\
\hline $\mathrm{AH}$ drug treatment before entry & 90.2 & 90.2 & 62.0 & 83.5 & 63.3 & 47.5 & 86.6 & 52.7 & 51.8 \\
\hline History of CV complications ${ }^{\S}$ & 36.1 & 36.4 & 15.0 & 12.3 & 2.4 & 6.9 & $100.0(\mathrm{CAD})$ & 8.4 & 30.6 \\
\hline Left ventricular hypertrophy & 21.0 & 20.7 & - & 12.3 & - & - & 21.9 & - & - \\
\hline Diabetes mellitus & 36.4 & 36.0 & 7.0 & 19.8 & $7.4^{\pi}$ & - & 28.3 & 12.1 & 13.2 \\
\hline Mean or median follow-up (years) & 4.9 & 4.9 & 4.1 & 3.0 & 3.7 & 1.1 & 2.7 & 3.7 & 2.7 \\
\hline
\end{tabular}

ACEI, angiotensin converting-enzyme inhibitor; ACM, all-cause mortality; AH, antihypertensive; BFMT, bendroflumethiazide; BP, blood pressure; CAD, documented coronary heart disease; CIMT, carotid intima-media thickening; CM, coronary mortality; COER, controlled onset-extended release; CV, cardiovascular; CVE, cardiovascular events; CVM, cardiovascular mortality; HCTZ, hydrochlorothiazide; MI, non-fatal myocardial infarction; PROBE, prospective randomized open blinded end-point study; S, non-fatal stroke. Acronyms of trials are explained in the Appendix. *Blood pressure at entry was measured on antihypertensive medication in previously treated patients. Negative values indicate tighter blood pressure control on old drug classes. "Significant difference in achieved blood pressure between randomized groups. ${ }^{\S}$ History of myocardial infarction, stroke excluding transient ischemic attack, or surgical or percutaneous revascularization. "Eighty-eight per cent of the SCOPE patients (24) allocated placebo were on open-label antihypertensive therapy, mainly with diuretics (62\%) or $\beta$-blockers (26\%). ${ }^{\natural}$ Fasting blood glucose concentration $>126 \mathrm{mg} / \mathrm{dl}(22)$.

December 2004 did not reveal new trials comparing ACE inhibitors to diuretics in addition to the 6 studies already analyzed in 2003 (7). The AASK trial (31) incorporated a comparison of ramipril with metoprolol, but only provided aggregate cardiovascular outcomes and therefore could not be included.

\section{AR1 Blockers vs. Conventional Therapy}

The LIFE trial (Table 2) compared the efficacy of losartan and atenolol as first-line treatments in hypertensive patients with left ventricular hypertrophy $(17,18)$. SCOPE $(24)$ was set up as a double-blind placebo-controlled trial. However, open-label antihypertensive drugs, which mainly consisted of diuretics, $\beta$-blockers, or both classes of old drugs, were added to the double-blind study medication in a considerably greater proportion of the patients randomized to placebo than in those allocated candesartan. There was no statistically significant heterogeneity between the results of these 2 trials (7). The levels of protection conferred against total mortality, cardiovascular death and myocardial infarction were similar between the control groups and the groups treated with an AR1 blocker. The pooled odds ratios were 0.91 (CI, 1.81$1.02 ; p=0.09$ ), 0.89 (CI, 0.77-1.04; $p=0.15$ ) and 1.08 (CI, $0.90-1.29 ; p=0.42)$, respectively. The corresponding estimates for stroke and all cardiovascular events were 0.77 (CI, $0.65-0.88 ; p=0.0002$ ) and 0.86 (CI, 0.77-0.95; $p=0.004$ ), respectively.

\section{New vs. Old Antihypertensive Drugs}

Our 2003 review demonstrated that across 15 trials $(8-21$, 23-25), outcomes for total and cardiovascular mortality, and myocardial infarction (Fig. 3) were consistent. The pooled odds ratios did not deviate from unity, averaging 0.98 (CI, $0.94-1.02 ; p=0.38), 1.00(\mathrm{CI}, 0.95-1.07 ; p=0.88)$ and 1.00 


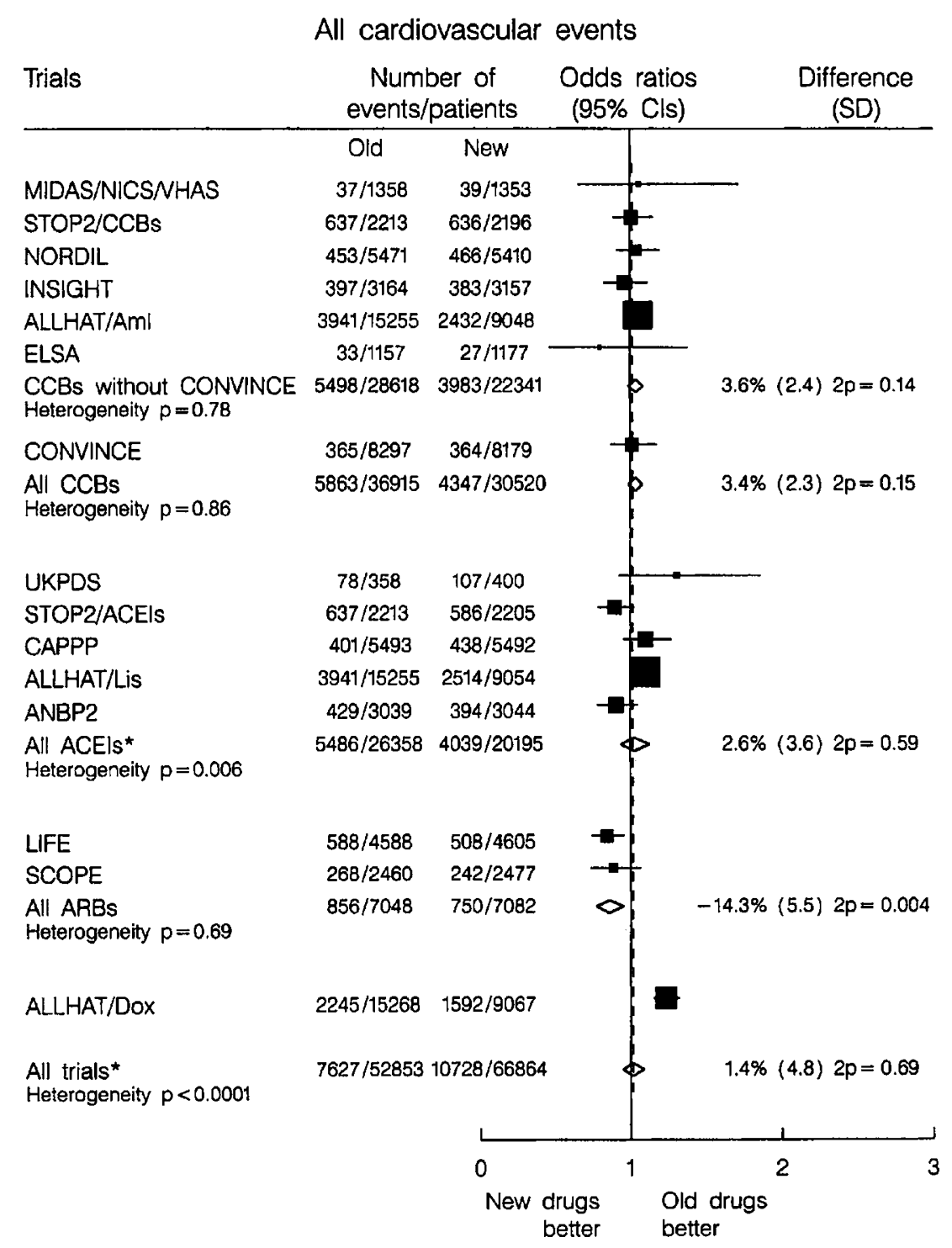

Fig. 1. Effects of antihypertensive treatment on all cardiovascular events in trials comparing new with old antihypertensive drugs. Asterisks indicate significant heterogeneity and pooled estimates calculated from a random effects model. Solid squares represent the odds ratios in trials and have a size proportional to the number of events. The 95\% confidence intervals for individual trials are denoted by lines and those for pooled odds ratios by diamonds. Acronyms of trials are defined in the Appendix. Reproduced with permission from Staessen et al. (7). For an update that includes information from the SHELL (30) and INVEST (29) trials, see the section entitled New vs. Old Antihypertensive Drugs.

(CI, 0.95-1.06; $p=0.87)$, respectively. In contrast, for all cardiovascular events (Fig. 1), stroke (Fig. 2) and heart failure, there was significant heterogeneity $(p<0.001)$ across the 15 trials $(8-21,23-25)$, which was largely due to the ALLHAT results $(14,21,32)$. First-line therapy with a diuretic provided more benefit than amlodipine and doxazosin with regard to heart failure and more benefit than lisinopril and doxazosin in the prevention of stroke. For all cardiovascular events and stroke, the overall odds ratios were 1.01 (CI, 0.95-1.09, $p=0.69$ ) and 0.98 (CI, 0.88-1.08; $p=0.64)$, respectively. Compared to conventional therapy, new drugs offered less protection against heart failure with a pooled odds ratio of 1.23 (CI, $1.03-1.47 ; p=0.02$ ).

\section{Calcium-Channel Blockers vs. AR1 Blockers}

Two secondary prevention trials (Table 2), IDNT2 (33-35) and VALUE (36-40), allowed a direct comparison between a dihydropyridine calcium-channel blocker and an AR1 blocker.

In the IDNT2 trial (33), 1,715 hypertensive patients with 
Fatal and non - fatal stroke

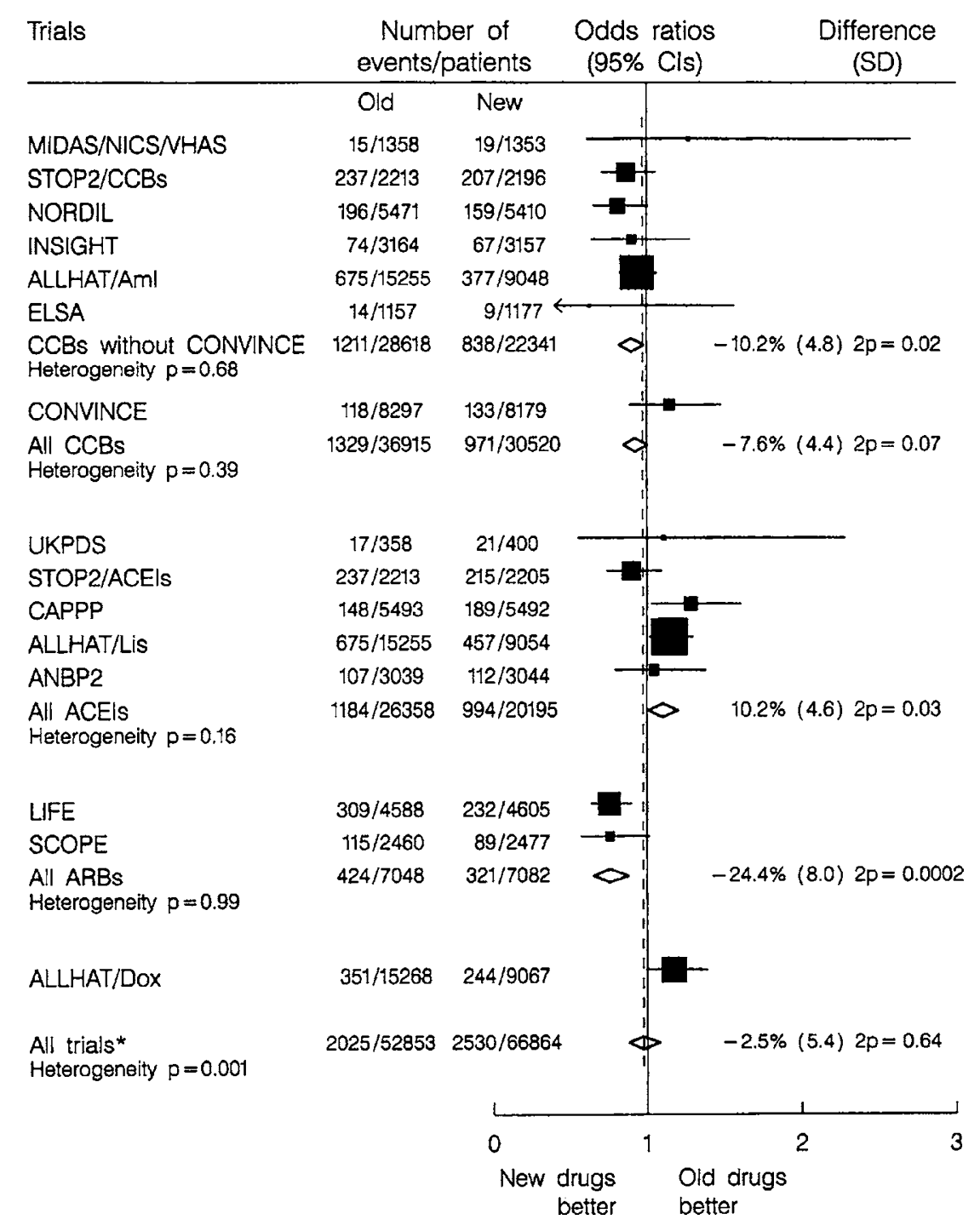

Fig. 2. Effects of antihypertensive treatment on fatal and non-fatal stroke in trials comparing new with old antihypertensive drugs. The asterisk indicates significant heterogeneity and pooled estimates calculated from a random effects model. For further explanation, see Fig. 1. Reproduced with permission from Staessen et al. (7). For an update that includes information from the SHELL (30) and INVEST (29) trials, see the section entitled New vs. Old Antihypertensive Drugs.

nephropathy due to type 2 diabetes were randomized to placebo, irbesartan (300 mg/day) or amlodipine (10 mg/day). The primary endpoint was a composite of a doubling of the baseline serum creatinine concentration, the development of end-stage renal disease, or death from any cause. The adjusted relative risk of the primary endpoint was 0.81 (CI, $0.67-0.99 ; p=0.03$ ) for irbesartan $v s$. placebo and 0.76 (CI, $0.63-0.92 ; p=0.005)$ for irbesartan vs. amlodipine with no difference between amlodipine and placebo (1.07; CI, 0.89$1.29 ; p=0.47)$. The doubling of the serum concentration of creatinine was considered to be mainly responsible for these results, because the between-group differences in the other constituents of the composite primary endpoint were not sta- tistically significant (33). The incidence of cardiovascular events was similar among the 3 groups. However, among the components of the composite cardiovascular outcome, there was a trend toward a decrease in strokes in patients receiving amlodipine $v s$. those randomized to the placebo group (hazard ratio, 0.62; CI, 0.35-1.22; $p=0.18$ ). Likewise, patients receiving amlodipine had a significantly lower rate of myocardial infarction when compared to placebo recipients $(0.58$; CI, $0.37-0.92 ; p=0.02)$. In contrast, patients receiving irbesartan experienced a lower incidence of heart failure than the placebo group $(0.72$; CI, $0.52-1.00 ; p=0.048)$ or the patients randomized to the amlodipine group $(0.65$; CI, 0.48-0.87; $p=0.004)$. 


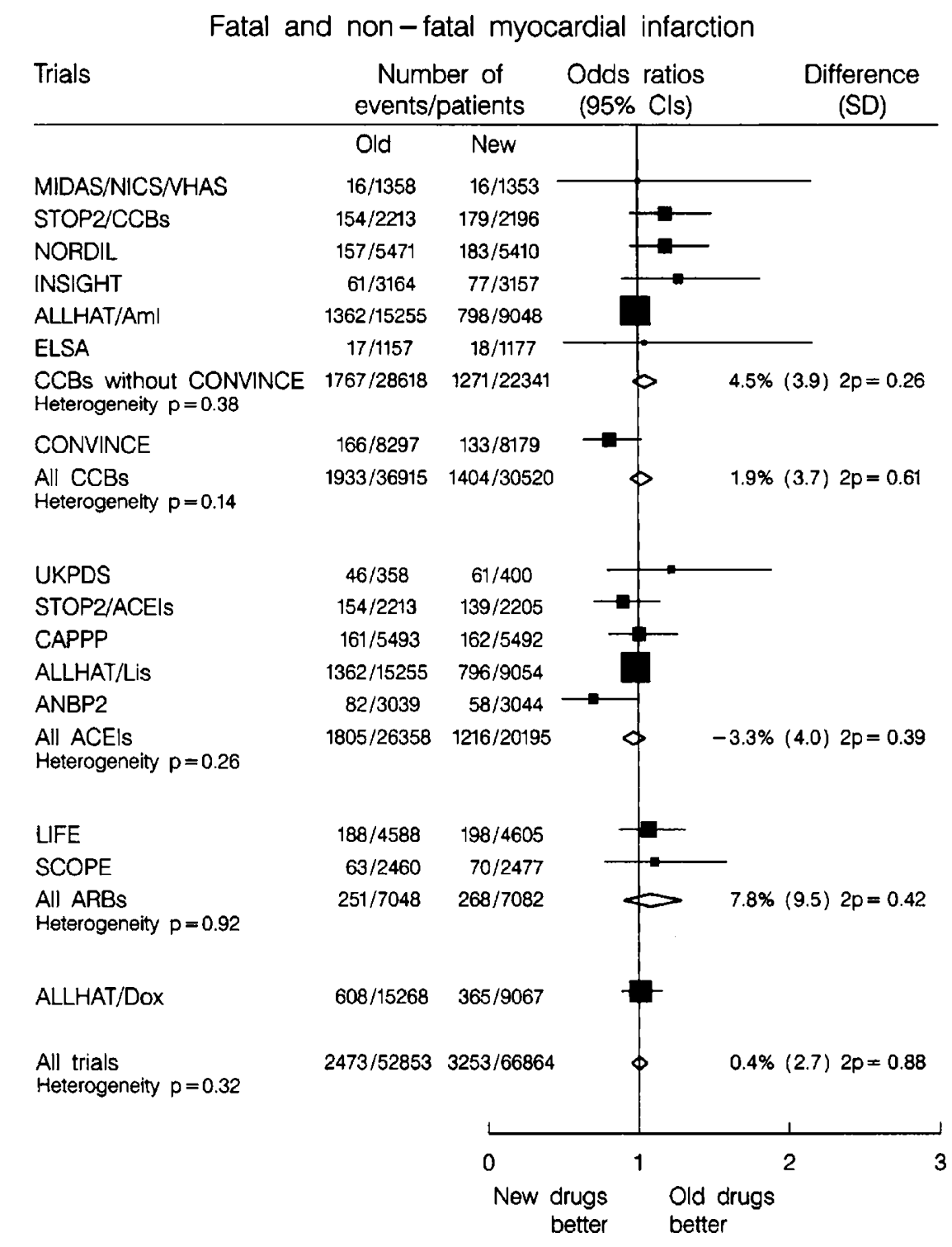

Fig. 3. Effects of antihypertensive treatment on fatal and non-fatal myocardial infarction in trials comparing new with old antihypertensive drugs. For further explanation, see Fig. 1. Reproduced with permission from Staessen et al. (7). For an update that includes information from the SHELL (30) and INVEST (29) trials, see the section entitled New vs. Old Antihypertensive Drugs.

The VALUE investigators undertook a double-blind clinical trial to test the hypothesis that, for the same degree of blood pressure lowering, inhibition of the renin system at the level of the AR1 would be more effective in the prevention of cardiac morbidity and mortality than calcium-channel blockade (36-40). Across 943 centers and 31 countries $(36,37,39)$, 15,245 high-risk patients were randomized to receive antihypertensive treatment based on either valsartan $(80-160 \mathrm{mg} /$ day) or amlodipine (5-10 mg/day) and followed-up for a median of 4.2 years. The VALUE investigators assumed that the primary endpoint, a composite of fatal and non-fatal cardiac endpoints, would run at a rate of 25 events per 1,000 patient-years (37). Within less than 5 years, the number of cardiac endpoints exceeded the projected number of 1,450 by 149. Cardiac endpoints occurred at similar rates in the two treatment groups, because the incidence of myocardial infarction was lower $(0.84 ; 0.72-0.98 ; p=0.02)$ on amlodipine than valsartan, whereas on amlodipine the risk of heart failure tended to be increased $(1.12 ; 0.97-1.30 ; p=0.12)$. The incidence of fatal and non-fatal stroke was lower $(0.87 ; 0.74-$ $1.02 ; p=0.08$ ) on amlodipine than valsartan. A unique feature of VALUE was the comprehensive assessment of cardiovascular risk at baseline (37) and the implementation of a strategy to stabilize risk at a high level across 6 strata based on gender and age (50-59, 60-69 and $\geq 70$ years). 
Table 2. Secondary Prevention Trials of Dihydropyridine Calcium-Channel Blockers and AR1 Blockers

\begin{tabular}{|c|c|c|c|c|c|c|c|}
\hline & LIFE & VALUE & ACTION & CAMELOT/Aml & IDNT2 & NICOLE & PREVENT \\
\hline Reference(s) & $(17,18)$ & $(39,40)$ & $(44)$ & $(41)$ & $(33,35)$ & $(46,47)$ & $(42,43)$ \\
\hline Degree of blinding & Double & Double & Double & Double & Double & Double & Double \\
\hline Number of patients & 9,193 & 15,245 & 7,665 & 1,318 & 1,715 & 819 & 825 \\
\hline Reference & 4,588 & 7,596 & 3,840 & 655 & 569 & 411 & 408 \\
\hline Calcium-channel/AR1 blocker & 4,605 & 7,649 & 3,825 & 663 & 1,146 & 408 & 417 \\
\hline \multicolumn{8}{|l|}{ Treatment } \\
\hline Reference & Atenolol & Amlodipine & Placebo & Placebo & Placebo & Placebo & Placebo \\
\hline Calcium-channel/AR1 blocker & Losartan & Valsartan & $\begin{array}{l}\text { Nifedipine } \\
\text { GITS }\end{array}$ & Amlodipine & $\begin{array}{l}\text { Amlodipine or } \\
\text { irbesartan }\end{array}$ & Nisoldipine & Amlodipine \\
\hline Primary endpoint & $\mathrm{CVM}+\mathrm{MI}+\mathrm{S}$ & $\mathrm{MI}+\mathrm{HF}$ & $\begin{array}{c}\mathrm{ACM}+\mathrm{MI}+\mathrm{A}+ \\
\mathrm{HF}+\mathrm{S}+\mathrm{PR}^{\#}\end{array}$ & $\begin{array}{c}\mathrm{CVM}+\mathrm{MI}+\mathrm{CAR}+\mathrm{A} \\
+\mathrm{CR}+\mathrm{HF}+\mathrm{S}+\mathrm{PAD}\end{array}$ & $\begin{array}{c}\text { ACM+ESRD }+ \\
\operatorname{SCrt}(2 \times)\end{array}$ & Rate of $\mathrm{COA}$ & Rate of CAA \\
\hline Mean age (years) & 66.9 & 67.2 & 63.5 & 57.3 & 58.9 & 60.3 & 56.9 \\
\hline \multicolumn{8}{|l|}{ Mean systolic/diastolic BP (mmHg)* } \\
\hline At randomization & $174 / 98$ & $155 / 88$ & $137 / 80$ & $129 / 78$ & $159 / 87$ & $129 / 78$ & $129 / 79$ \\
\hline Difference during follow-up ${ }^{\dagger}$ & $+1.1 \%-0.2$ & $-2.2+-1.6^{\ddagger}$ & $+6.0 \%+3.0$ & $+4.8^{\ddagger} /+3.0^{\ddagger}$ & $+5.0^{\ddagger} /+3.0^{\ddagger}$ & $+9.1 \%+3.3$ & $+6.8^{\star} /+3.7^{\ddagger}$ \\
\hline \multicolumn{8}{|l|}{ Proportion of patients (\%) } \\
\hline Women & 54.0 & 42.4 & 20.6 & 25.4 & 33.5 & 20.0 & 19.9 \\
\hline Hypertension at entry & 100.0 & 100.0 & 51.9 & 60.8 & $100.0^{\mathbb{4}}$ & 40.6 & - \\
\hline History of CHD (MI) & $16.0(-)^{\mathrm{s}}$ & $45.8(-)$ & $100.0(50.9)$ & $100.0(37.6)$ & $16.5(-)$ & $100.0(42.5)$ & $100.0(44.9)$ \\
\hline History of stroke & $7.9^{\&}$ & $19.8^{\&}$ & - & 3.9 & 11.6 & - & 3.0 \\
\hline Diabetes mellitus & 13.0 & 31.7 & 14.5 & 18.6 & 100.0 & 10.4 & $0 \equiv$ \\
\hline \multicolumn{8}{|l|}{ Concomitant therapy (\%) } \\
\hline Lipid-lowering drugs & - & 46.4 & 68.5 & 83.7 & - & 41.0 & 27.3 \\
\hline Antiplatelet agents & - & 72.6 & 86.0 & 94.9 & - & - & - \\
\hline Mean or median follow-up (years) & 4.8 & 4.2 & 4.9 & 2.0 & 2.6 & 3.0 & 3.0 \\
\hline
\end{tabular}

AR1, angiotensin type 1 receptor; A, refractory or hospitalized angina pectoris; ACM, all-cause mortality; BP, blood pressure; CAA, atheromatosis of the carotid artery; COA, coronary atheromatosis; CAR, resuscitated cardiac arrest; CHD, coronary heart disease; CR, coronary revascularization; CVM, cardiovascular mortality; ESRD, end-stage renal disease; HF, heart failure; MI, non-fatal myocardial infarction; PAD, peripheral arterial disease; PR, peripheral revascularization; S, non-fatal stroke; $\mathrm{SCrt}(2 \times)$, doubling of the serum creatinine concentration. Acronyms of trials are explained in the Appendix. *Blood pressure at entry was always measured on antihypertensive medication in previously treated patients. Negative values indicate tighter blood pressure control in the reference group. tSignificant difference in achieved blood pressure between randomised groups. ${ }^{\$}$ The blood pressure differences between the amlodipine and irbesartan groups were non-significant. "Primary endpoint for efficacy. "Hypertension is a blood pressure $\geq 135 \mathrm{mmHg}$ systolic or $\geq 85 \mathrm{mmHg}$ diastolic or use of antihypertensive medications. ${ }^{\$}$ In LIFE, all patients had electrocardiographic left ventricular hypertrophy. ${ }^{\&}$ Stroke includes transient ischemic attack. ${ }^{=}$Fasting blood glucose concentration $\geq 200 \mathrm{mg} / \mathrm{dl}$ (43).

\section{Placebo-Controlled Secondary Prevention Trials}

Several secondary prevention trials have compared the levels of cardiovascular protection conferred by conventional antihypertensive therapy and the combination of conventional antihypertensive therapy and new antihypertensive agents. In 5 trials with 12,342 randomized patients (Table 2), the experimental agent was a dihydropyridine calcium-channel blocker: amlodipine in CAMELOT/Aml (41), PREVENT $(42,43)$, and IDNT2 (33-35); nifedipine GITS (gastro-intestinal therapeutic system) in ACTION $(44,45)$; and nisoldipine in NICOLE $(46,47)$. In 9 trials with 43,227 randomized patients (Table 3 ), the investigational drug was an ACE inhibitor: enalapril in CAMELOT/En (41) and SCAT (48); perindopril alone in EUROPA (49) and PROGRESS/ Per $(50,51)$ or in combination with indapamide in PROGRESS/Com $(50,51)$; ramipril in DIABHYCAR (5254), HOPE $(55,56)$ and PART2 (57); and trandolapril in PEACE (58). All patients randomized in these trials were high risk patients with a history of cardiovascular disease and/ or diabetes mellitus (54-56), nephropathy $(33,35)$, documented coronary heart disease $(41,43,44,46-49,57,58)$ or a previous cerebrovascular accident $(51,59)$.

All $(33,41,44,49,54,55,58)$ but $5(43,46,48,51,57)$ of the placebo-controlled secondary prevention trials had a composite primary endpoint (Tables 2 and 3). In 3 trials (41), the composite endpoint included coronary $(41,58)$ or peripheral (44) revascularization procedures. In 4 trials the primary end- 
Table 3. Placebo-Controlled Trials of ACE Inhibitors for Secondary Prevention

\begin{tabular}{|c|c|c|c|c|c|c|c|c|c|}
\hline \multirow{2}{*}{ 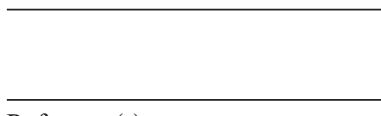 } & \multirow{2}{*}{ CAMELOT/En } & \multirow{2}{*}{ DIABHYCAR } & \multirow{2}{*}{ EUROPA } & \multirow{2}{*}{ HOPE } & \multirow{2}{*}{ PART2 } & \multirow{2}{*}{ PEACE } & \multicolumn{2}{|c|}{ PROGRESS/ PROGRESS/ } & \multirow{2}{*}{ SCAT } \\
\hline & & & & & & & Per & Com & \\
\hline Reference(s) & $(41)$ & $(52,54)$ & (49) & $(55,56)$ & $(57)$ & $(58)$ & $(51,59)$ & $(51,59)$ & (48) \\
\hline Degree of blinding & Double & Double & Double & Double & Double & Double & Double & Double & Double \\
\hline Number of patients & 1,328 & 4,912 & 12,218 & 9,297 & 617 & 8,290 & 2,561 & 3,544 & 460 \\
\hline Reference & 655 & 2,469 & 6,108 & 4,652 & 309 & 4,132 & 1,280 & 1,774 & 231 \\
\hline ACE inhibitor & 673 & 2,443 & 6,110 & 4,645 & 308 & 4,158 & 1,281 & 1,770 & 229 \\
\hline \multicolumn{10}{|l|}{ Treatment } \\
\hline Reference & Placebo & Placebo & Placebo & Placebo & Placebo & Placebo & Placebo & Placebo & Placebo \\
\hline ACE inhibitor & Enalapril & Ramipril & Perindopril & Ramipril & Ramipril & Trandolapril & Perindopril & $\begin{array}{l}\text { Perindopril + } \\
\text { indapamide }\end{array}$ & Enalapril \\
\hline Primary endpoint & $\begin{array}{c}\mathrm{CVM}+\mathrm{MI}+\mathrm{CAR} \\
+\mathrm{A}+\mathrm{CR}+\mathrm{HF}+\mathrm{S} \\
+\mathrm{PAD}\end{array}$ & $\begin{array}{c}\mathrm{CVM}+\mathrm{MI}+\mathrm{S}+\mathrm{HF}+ \\
\text { ESRD }\end{array}$ & CVM+MI+CAR & $\mathrm{CVM}+\mathrm{MI}+\mathrm{S}$ & Rate of $\mathrm{COA}$ & $\mathrm{CVM}+\mathrm{MI}+\mathrm{CR}$ & S & S & Rate of CAA \\
\hline Mean age (years) & 57.9 & 65.1 & 60.0 & 66.0 & 60.5 & 64.0 & 65.0 & 63.0 & 61.0 \\
\hline \multicolumn{10}{|l|}{ Mean systolic/diastolic BP (mmHg) } \\
\hline At randomization & $129 / 77$ & $145 / 82$ & $137 / 82$ & $139 / 79$ & $133 / 79$ & $133 / 78$ & $144 / 84$ & $149 / 87$ & $130 / 78$ \\
\hline Difference during follow-up ${ }^{\dagger}$ & $+5.6 \%+3.4$ & $+1.5^{\ddagger} /+0.3$ & $+5.0^{\ddagger} /+2.0^{\ddagger}$ & $+3.0^{\ddagger} /+1.0^{\ddagger}$ & $+5.0^{\ddagger} /+4.0^{\ddagger}$ & $+2.0 \%+1.2$ & $+4.9^{\ddagger} /+2.8^{\ddagger}$ & $+12.3 \%++5.0^{\ddagger}$ & $+4.0^{\ddagger} /+2.0^{\ddagger}$ \\
\hline \multicolumn{10}{|l|}{ Proportion of patients $(\%)$} \\
\hline Women & 27.6 & 30.1 & 14.6 & 26.7 & 18.0 & 18.0 & 31.6 & 29.4 & 10.9 \\
\hline Hypertension at entry & 60.0 & 55.7 & $27.1^{\S}$ & 46.8 & - & 45.5 & 39.6 & 53.7 & 35.2 \\
\hline History of CHD (MI) & $100.0(39.0)$ & $-(6.0)$ & $100.0(64.7)$ & $81.0(52.6)$ & $68.0(42.0)$ & $100.0(55.0)$ & $13.5(-)$ & $17.9(-)$ & $100.0(70.4)$ \\
\hline History of stroke & 4.3 & 4.2 & $3.5^{\#}$ & $10.9^{\#}$ & $10.0^{\#}$ & 6.5 & $100.0^{\#}$ & $100.0^{\#}$ & - \\
\hline Diabetes mellitus & 18.7 & 100.0 & 12.3 & 38.5 & 8.5 & 17.0 & 13.2 & 12.0 & 10.9 \\
\hline \multicolumn{10}{|l|}{ Concomitant therapy (\%) } \\
\hline Lipid-lowering drugs & $83.0^{\curvearrowleft}$ & 28.5 & $63.0^{\natural}$ & 28.5 & 29.5 & 70.0 & 15.0 & 15.0 & $\sim 50.0^{\S}$ \\
\hline Antiplatelet agents & $95.0^{\natural}$ & 18.7 & $91.0^{\natural}$ & 76.1 & 81.0 & 90.5 & 77.0 & 77.0 & 89.9 \\
\hline Mean or median follow-up (years) & 2.0 & 3.9 & 4.2 & 5.0 & 4.0 & 4.8 & 4.0 & 4.0 & 4.0 \\
\hline
\end{tabular}

$\mathrm{ACE}$, angiotensin converting-enzyme; A, refractory or hospitalized angina pectoris; CAA, atheromatosis of the carotid artery; COA, coronary atheromatosis; CAR, resuscitated cardiac arrest; CHD, coronary heart disease; CR, coronary revascularization; CVM, cardiovascular mortality; ESRD, end-stage renal disease; HF, heart failure; MI, non-fatal myocardial infarction; PAD, peripheral arterial disease; S, non-fatal stroke. Acronyms of trials are explained in the Appendix. *Blood pressure at entry was always measured on antihypertensive medication in previously treated patients. The positive values indicate tighter blood pressure control on ACE inhibitors. ${ }^{\star}$ Significant difference in achieved blood pressure between randomised groups. ${ }^{\S}$ Hypertension is a blood pressure $\geq 160 \mathrm{mmHg}$ systolic, $\geq 90 \mathrm{mmHg}$ diastolic (PROGRESS) or $\geq 95 \mathrm{mmHg}$ diastolic (EUROPA), or use of antihypertensive medications. "Stroke includes tran-

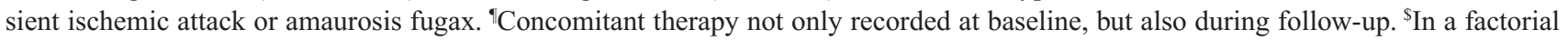
design, the patients were also randomized to simvastatin or placebo.

point consisted only of the rate of change of carotid $(43,48)$ or coronary $(46,57)$ atherosclerosis, and hard endpoints, such as stroke or myocardial infarction, were only secondary outcomes. The use of composite endpoints with varying definitions (Tables 2 and 3) and the wide range of secondary endpoints made obtaining pooled estimates for overall treatment effects difficult. CAMELOT (41) and PEACE (58) only reported non-fatal cases of myocardial infarction. Stroke included transient ischemic attack in CAMELOT (41) and was limited to non-fatal events in PART2 (57).

Among the 5 trials of dihydropyridine calcium-channel blockers $(35,41,43,44,47)$, there was no heterogeneity in the results with regard to stroke $(p=0.81)$, myocardial infarction $(p=0.16)$ and the composite of all cardiovascular events, which also included procedures and revascularization $(p=0.52)$. The pooled odds ratios were: 0.71 (CI, 0.55-0.92; $p=0.0015), 0.97$ (CI, 0.83-1.13; $p=0.70$ ), and 0.78 (CI, $0.72-0.85 ; p<0.0001)$, respectively. When the analysis was limited to the 3 trials involving amlodipine as the experimental agent $(35,41,43)$, these pooled estimates were $0.60(\mathrm{CI}$, $0.36-0.97 ; p=0.038$ ) for stroke, 0.69 (CI, 0.49-0.97; $p=0.033$ ) for myocardial infarction, and 0.73 (CI, $0.62-0.85$; $p=0.0001$ ) for cardiovascular events.

Among the placebo-controlled trials of ACE inhibitors (41, $48,49,51,54,55,57,58)$, there was significant heterogeneity $(p \leq 0.001)$ in the results for all cardiovascular endpoints and stroke, but not for myocardial infarction $(p=0.25)$. In these analyses, the 2 strata in the PROGRESS trial were treated 


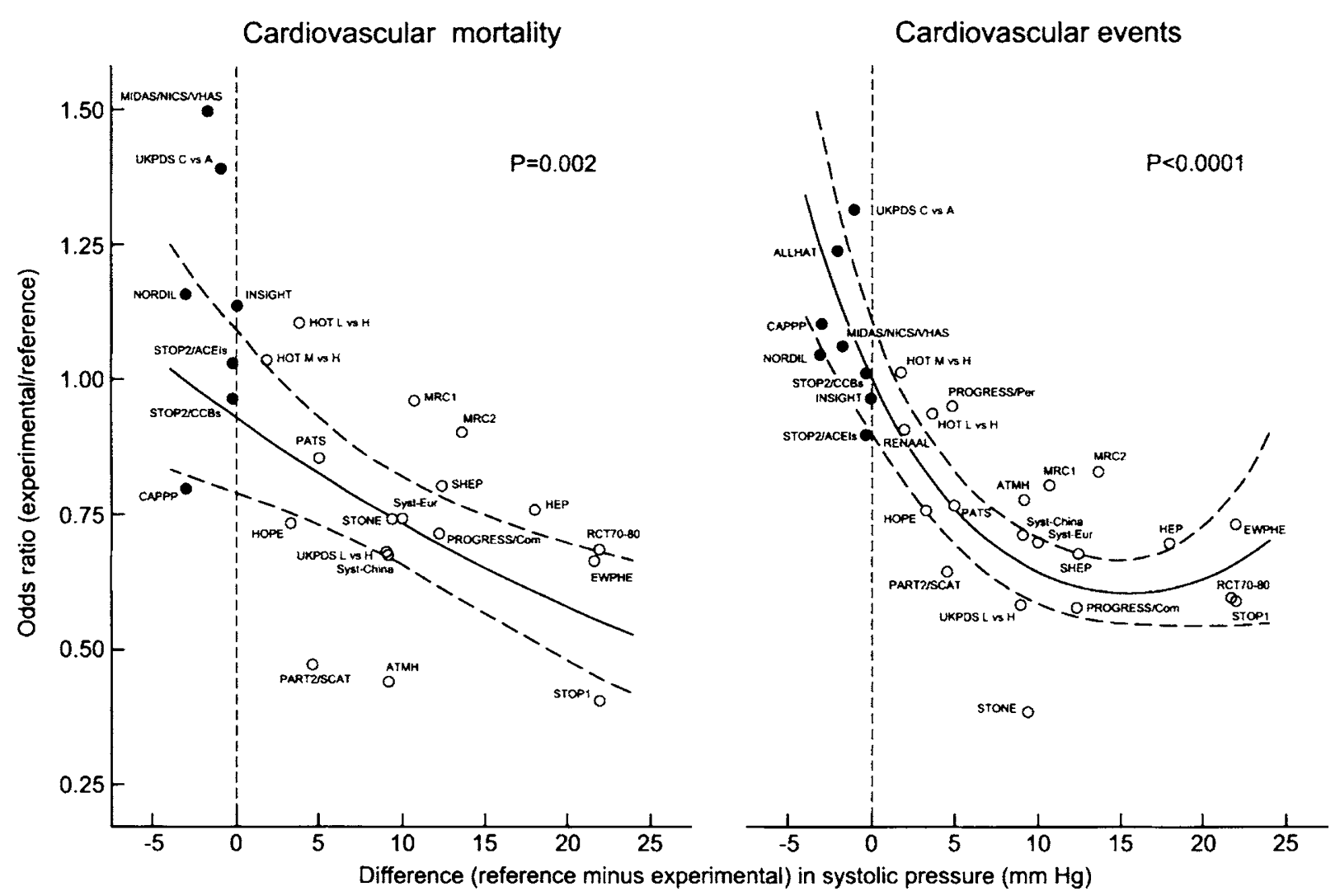

Fig. 4. Odds ratios for cardiovascular mortality (left panel) and all cardiovascular events (right panel) in relation to corresponding differences in systolic blood pressure (SBP). Odds ratios were calculated for experimental vs. reference treatment. Blood pressure differences were obtained by subtracting the levels achieved in experimental groups from those achieved in the reference groups. Negative values indicate that the control treatment realized tighter blood pressure control than the reference treatment. The regression lines were plotted with 95\% confidence interval and were weighted for the inverse of the variance of the individual odds ratios. Open symbols denote placebo-controlled studies or trials with an untreated control group. Closed symbols indicate actively controlled trials. Acronyms of trials are defined in the Appendix. Reproduced with permission from Staessen et al. (5).

separately (monotherapy with perindopril vs. placebo; and perindopril plus indapamide vs. matching placebos). Cardiovascular events included revascularization procedures in CAMELOT (41) and total mortality in SCAT (48), but not in the other trials $(49,51,54,55,57,58)$. Across the available studies $(41,48,49,51,54,55,57,58)$, the pooled odds ratios for ACE inhibition vs. placebo were highly significant ( $p<0.0001$ ), amounting to 0.81 (CI, 0.77-0.86) for cardiovascular events, 0.77 (CI, 0.69-0.84) for stroke, and 0.80 (CI, 0.73-0.86) for myocardial infarction. In sensitivity analyses, we excluded EUROPA (49) and PROGRESS/Per (51), 2 trials of perindopril given in monotherapy, and DIABHYCAR (54), in which the difference in systolic blood pressure (SBP) between the ramipril and placebo group was only $1.5 \mathrm{mmHg}$. These exclusions removed the heterogeneity for stroke $(p=0.11)$ and decreased the common odds ratio for stroke to 0.63 (CI, 0.56-0.72; $p<0.0001$ ).

In addition to the endpoints reviewed above, several secondary prevention trials, including $\mathrm{AASK}(31,60)$, ABCD
(61-65), BENEDICT (66, 67), CALM (68), HOPE (56), IRMA2 (69), REIN (70), RENAAL (71), IDNT2 (33-35) and a number of earlier published smaller trials (72), demonstrated that ACE inhibitors, AR1 blockers or their combination reduce the progression of renal impairment in patients with microalbuminuria or proteinuria in the presence or absence of diabetes mellitus.

\section{Role of Blood Pressure Reduction}

In $2001(5,6)$, we computed the relation between the odds ratios of experimental vs. reference treatment and the corresponding baseline-corrected differences in SBP between randomized groups. Our meta-regression analysis (6) involved 30 trials including 149,407 randomized patients: 9 actively controlled trials (MIDAS (8), CAPPP $(9,73)$, NICS (10), STOP2 (11), INSIGHT (12, 74), NORDIL (13), ALLHAT/ Dox (14), VHAS (26), and UKPDS $(16,75)$ ); the HOT trial (76), which investigated 3 levels of diastolic blood pressure 


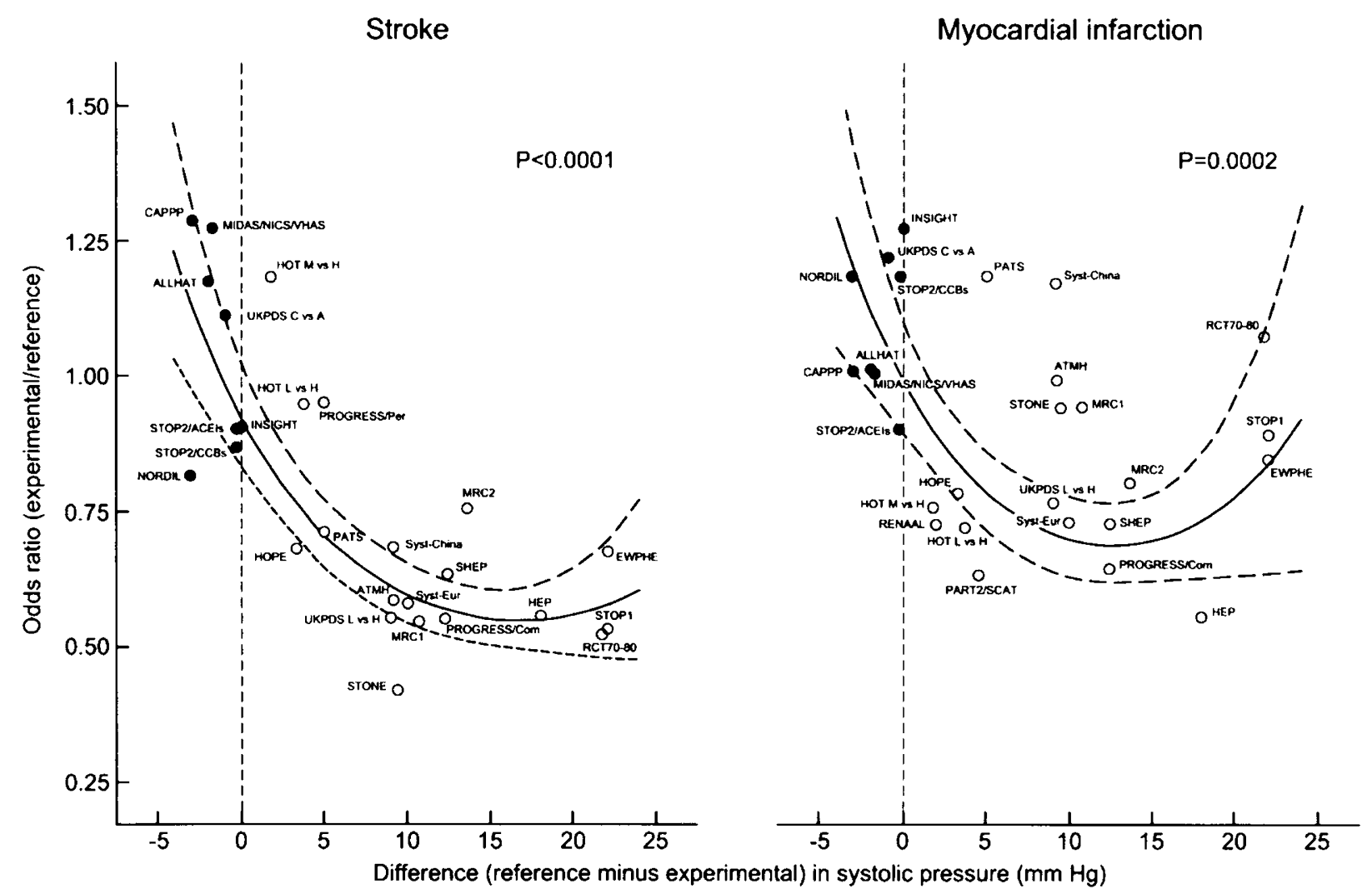

Fig. 5. Odds ratios for fatal and non-fatal stroke (left panel) and fatal and non-fatal myocardial infarction (right panel) in relation to corresponding differences in systolic blood pressure (SBP). Odds ratios were calculated for experimental vs. reference treatment. Blood pressure differences were obtained by subtracting the levels achieved in experimental groups from those achieved in reference groups. Negative values indicate that the control treatment realized tighter blood pressure control than the reference treatment. The regression lines were plotted with 95\% confidence interval and were weighted for the inverse of the variance of the individual odds ratios. Open symbols denote placebo-controlled studies or trials with an untreated control group. Closed symbols indicate actively controlled trials. Acronyms of trials are defined in the Appendix. Reproduced with permission from Staessen et al. (5).

control; 3 placebo-controlled trials in isolated systolic hypertension (SHEP $(77,78)$, Syst-China $(79,80)$ and Syst-Eur $(81-83))$; 6 placebo-controlled trials in normotensive or hypertensive patients at high cardiovascular risk (HOPE (55, 56), PART2 (57), PATS (84), PROGRESS (51, 59, 85), SCAT (48), and RENAAL (71)); and 11 older trials testing the efficacy of antihypertensive drugs against no treatment (HEP (86) and OSLO (27)) or placebo (ATMH (87), EWPHE (88, 89), HSCS (90), MRC1 (91), MRC2 (92), STOP1 (93), STONE (94), USPHS (95), and VACS (96)). Seven studies were excluded for the following reasons: fewer than 100 patients had been randomized (97-99), follow-up was less than 2 years $(100,101)$, insufficient information was published on achieved SBP (HDFP $(102,103))$ or non-fatal outcomes (CASTEL (104)), and/or randomization took place between usual and referred care (CASTEL (104) and HDFP $(102,103))$.

As previously reported $(5,6,105)$, the meta-regression line relating the odds ratios for cardiovascular mortality (Fig. 4, left panel) to the corresponding within-trial differences in SBP was linear. For all cardiovascular events (Fig. 4, right panel), stroke (Fig. 5, left panel) and myocardial infarction (Fig. 5, right panel), these relations were curvilinear. For these fatal and non-fatal outcomes combined, there was no further benefit if the within-trial differences in SBP exceeded $\sim 15 \mathrm{mmHg}$. Because, in our meta-regression analysis $(5,6$, 105), the odds ratios respected the randomization, and because within each trial patients had similar characteristics at entry, adjustment for the baseline SBP did not materially alter the position of the regression lines.

In our first reviews $(5,6,105)$, we compared observed odds ratios and those that could be predicted by meta-regression from the baseline-adjusted differences in achieved SBP between randomized groups. Among 6 trials of new vs. old drugs (ALLHAT/Dox (14), CAPPP (9, 73), MIDAS (8), NICS (10), NORDIL (13), and VHAS (26)) and 4 placebocontrolled trials (HOPE $(55,56)$, PART2 (57), PROGRESS $(51,59,85)$, and SCAT $(48))$, the gradients in achieved SBP 
Table 4. Observed Odds Ratios and Odds Ratios Predicted by Between-Group Differences in Systolic Blood Pressure in Trials of Blood Pressure Lowering Therapies

\begin{tabular}{|c|c|c|c|c|c|c|c|}
\hline \multirow[b]{2}{*}{ Outcome } & \multirow[b]{2}{*}{ Trial—subgroup } & \multirow{2}{*}{$\begin{array}{c}\text { Patients } \\
\text { (n) }\end{array}$} & \multirow{2}{*}{$\begin{array}{c}\text { Events } \\
(\%)\end{array}$} & \multirow{2}{*}{$\begin{array}{c}\Delta \mathrm{SBP}^{*} \\
(\mathrm{mmHg})\end{array}$} & \multicolumn{2}{|c|}{ Odds ratio } & \multirow[b]{2}{*}{$p^{\S}$} \\
\hline & & & & & Observed $^{\dagger}$ & Predicted & \\
\hline CVM & ACTION (44) & 7,665 & 4.6 & +6.0 & $1.01(0.82-1.24)$ & $0.81(0.72-0.90)$ & 0.06 \\
\hline CVM & HYVET/BP (25) & 857 & 6.2 & +22.5 & $1.19(0.67-2.18)$ & $0.55(0.44-0.68)$ & 0.02 \\
\hline CVE & AASK $(31,60)$ & 1,094 & 10.4 & +16.0 & $0.88(0.58-1.32)$ & $0.60(0.55-0.67)$ & 0.07 \\
\hline CVE & ACTION (44) & 7,665 & 13.6 & +6.0 & $0.94(0.85-1.05)$ & $0.73(0.67-0.80)$ & 0.0001 \\
\hline CVE & ANBP2 (23) & 6,083 & 13.5 & -2.0 & $0.90(0.78-1.05)$ & $1.15(1.00-1.31)$ & 0.05 \\
\hline CVE & PROGRESS/Per (51) & 2,561 & 18.1 & +5.0 & $0.96(0.80-1.15)$ & $0.76(0.69-0.85)$ & 0.03 \\
\hline MI & ACTION (44) & 7,665 & 6.8 & +6.0 & $1.04(0.88-1.24)$ & $0.76(0.69-0.84)$ & 0.002 \\
\hline MI & ALLHAT/Lis $(21)$ & 24,309 & 15.4 & -2.3 & $0.98(0.90-1.08)$ & $1.14(0.98-1.34)$ & 0.08 \\
\hline MI & ALLHAT/Lis—patients $\geq 65$ years $(21)$ & 13,969 & - & -3.0 & $1.01(0.91-1.12)^{\natural}$ & $1.20(1.01-1.43)$ & 0.08 \\
\hline MI & ANBP2 (23) & 6,083 & 2.3 & -2.0 & $0.70(0.49-1.00)$ & $1.08(0.95-1.23)$ & 0.02 \\
\hline MI & VALUE $(39,40)$ & 15,245 & 4.5 & -2.2 & $0.84(0.72-0.98)$ & $1.02(0.93-1.11)$ & 0.03 \\
\hline Stroke & EUROPA (49) & 12,218 & 1.6 & +5.0 & $0.96(0.68-1.24)$ & $0.71(0.65-0.77)$ & 0.06 \\
\hline Stroke & NORDIL (13) & 10,881 & 3.3 & -3.1 & $0.81(0.65-1.01)$ & $1.14(0.97-1.35)$ & 0.01 \\
\hline Stroke & PROGRESS/Per (51) & 2,561 & 12.6 & +5.0 & $0.95(0.77-1.19)$ & $0.71(0.64-0.85)$ & 0.02 \\
\hline
\end{tabular}

The table includes specific outcomes, for which the significance of the difference between observed vs. predicted odds ratios was significant or borderline significant. Endpoints tested included cardiovascular mortality (CVM), cardiovascular events (CVE) consisting of $\mathrm{CVM}$, fatal and non-fatal stroke, and fatal and non-fatal myocardial infarction (MI), as available in 44 trials. ${ }^{*} \Delta \mathrm{SBP}$ is the difference in systolic blood pressure between randomized groups in $\mathrm{mmHg}$, negative values indicating tighter blood pressure on control than on reference treatment. ${ }^{\dagger}$ Observed odds ratios with exact $95 \%$ confidence intervals were calculated from the number of events (control/experimental) and the number of patients (Table 2) per group randomized in each trial by use of $2 \times 2$ contingency tables. ${ }^{\star}$ Odds ratio (95\% confidence interval) predicted by meta-regression $(5,6) .{ }^{\S}$ Significance of the difference between observed and predicted odds ratios. "Relative risks as reported in reference (21).

ranged from $1.8 \mathrm{mmHg}(8)$ to $12.0 \mathrm{mmHg}(51)$. Differences between observed and predicted odds ratios were not significant apart from those for stroke in NORDIL (13) and PROGRESS/Per $(51,59,85)$. In the former study (13), the risk was lower in patients on diltiazem than on old drugs despite the fact that the SBP was $3.1 \mathrm{mmHg}$ higher on the calcium-channel blocker (Table 4). In PROGRESS/Per (51), monotherapy with perindopril reduced SBP by $5.0 \mathrm{mmHg}$ compared to placebo, but had no influence on stroke recurrence or the incidence of all cardiovascular events.

In our 2003 update (7), we considered 7 additional studies allowing comparison of outcomes on new $v s$. old drugs (ALLHAT (21), ANBP2 (23), CONVINCE (19), ELSA (20, 22), HYVET/AD (25), LIFE $(17,18,106,107)$, and SCOPE (24, $108,109)$ ). Taking conventional therapy with diuretics and $\beta$ blockers as a reference, the achieved SBP was higher on amlodipine in ALLHAT/Aml $(1.1 \mathrm{mmHg})$, on lisinopril in ALLHAT/Lis $(2.3 \mathrm{mmHg})$, and on ACE inhibitors in ANBP2 (2.0 mmHg). In contrast, in LIFE/All (1.1 mmHg) and LIFE/ $\mathrm{DM}(3.0 \mathrm{mmHg})$ as well as in SCOPE $(3.2 \mathrm{mmHg})$, SBP was significantly higher in the reference group on conventional therapy than in the patients allocated losartan or candesartan, respectively. In general, there were no significant differences between the observed and predicted odds ratios in the reviewed outcomes in any of these trials (7). Myocardial infarction $(p=0.02)$ and consequently all cardiovascular events $(p=0.05)$ in the ANBP2 trial (23) constituted the only significant exceptions (Table 4). In the ANBP2 patients randomized to the ACE inhibition group, SBP was on average $2.0 \mathrm{mmHg}$ higher than in those allocated to receive diuretic treatment (23). The predicted odds ratios therefore tended to be higher than unity, whereas for all cardiovascular events (1.15 vs. 0.90$)$ and myocardial infarction (1.08 vs. 0.70$)$ the opposite was observed. For myocardial infarction (Table 4), borderline differences between predicted $v s$. observed odds ratios in favor of ACE inhibition were also observed in ALLHAT/Lis, both in all patients $(1.14 v s .0 .98 ; p=0.08)$ and in those aged 65 years or more $(1.20 v s .1 .01 ; p=0.08)$.

In our 2003 update (7), we also reviewed 2 trials that compared tight to conventional blood pressure control (AASK $(31,60,110)$ and ABCD/NT (65)) and 5 placebo-controlled designs (DIABHYCAR (52-54), HYVET/BP (25), IDNT2 (33-35), NICOLE $(46,47)$, and PREVENT $(42,43))$. For these 7 trials $(25,35,43,47,54,60,65)$, observed and predicted odds ratios were similar with the exception of cardiovascular mortality in HYVET/BP (Table 4). In spite of a 22.5 $\mathrm{mmHg}$ lower SBP in the patients randomized to active treatment than in those left untreated, cardiovascular mortality did not decrease (observed vs. predicted odds ratios, 1.19 vs. 0.55; $p=0.02$ ). For all cardiovascular events in AASK (60), the 


\begin{tabular}{|c|c|c|c|c|c|c|c|c|}
\hline \multirow{2}{*}{$\frac{\text { DHP }}{\text { Nifedipine }}$} & \multirow{2}{*}{$\frac{\begin{array}{l}\text { Dosage } \\
(\mathrm{mg} / \mathrm{d})\end{array}}{30-60}$} & \multirow{2}{*}{$\begin{array}{l}\begin{array}{l}\text { Trial } \\
(n)\end{array} \\
\text { ACTION } \\
(7665)\end{array}$} & \multirow{2}{*}{$\begin{array}{c}\begin{array}{r}\% \text { with } \\
\text { stroke }\end{array} \\
2.3\end{array}$} & \multicolumn{2}{|c|}{$\begin{array}{c}\text { STROKE } \\
\text { Observed and predicted odds ratios }(95 \% \mathrm{Cl})\end{array}$} & \multirow{2}{*}{$\frac{P}{0.38}$} & \multirow{2}{*}{$\begin{array}{c}\begin{array}{c}\mathrm{BP} \\
(\mathrm{mm} \mathrm{Hg})\end{array} \\
137 / 80\end{array}$} & \multirow{2}{*}{$\frac{\begin{array}{c}\Delta \mathrm{SBP} \\
(\mathrm{mmHg})\end{array}}{6.0}$} \\
\hline & & & & $\frac{10.78}{T 0.68}$ & 6 & & & \\
\hline Nisoldipine & $20-40$ & $\begin{array}{l}\text { NICOLE } \\
(819)\end{array}$ & 1.3 & $0 . 1 2 \longdiv { \frac { 1 } { T _ { 0 . 6 1 } } }$ & $D 2.27$ & 0.93 & $129 / 78$ & 9.1 \\
\hline \multirow[t]{3}{*}{ Amlodipine } & $5-10$ & $\begin{array}{l}\text { PREVENT } \\
(825)\end{array}$ & 1.2 & T0.66 & $\Rightarrow 4.29$ & 0.60 & $129 / 78$ & 6.8 \\
\hline & & $\begin{array}{l}\text { CAMELOT* } \\
(1318)\end{array}$ & 1.4 & \begin{aligned} 0.73 \\
\multicolumn{1}{c}{0.79}\end{aligned} & & 0.82 & $129 / 78$ & 4.8 \\
\hline & & $\begin{array}{l}\text { IDNT2 } \\
(1136)\end{array}$ & 3.6 & $\frac{0.58}{70.71}$ & & 0.53 & $159 / 87$ & 5.0 \\
\hline \multicolumn{9}{|l|}{ ACEI } \\
\hline \multirow[t]{3}{*}{ Ramipril } & 10 & $\begin{array}{l}\text { HOPE } \\
(9297)\end{array}$ & 4.1 & $\frac{0.68}{10.77}$ & & 0.32 & $139 / 79$ & 3.3 \\
\hline & $5-10$ & $\begin{array}{l}\text { PART2 } \\
(617)\end{array}$ & 1.8 & $\mathbf{T} .71$ & $\stackrel{1.67}{1.67} 5.75$ & 0.18 & $133 / 79$ & 5.0 \\
\hline & 1.25 & $\begin{array}{l}\text { DIABHYCAR } \\
(4912)\end{array}$ & 4.8 & 70.8 & 1.03 & 0.21 & $145 / 82$ & 1.5 \\
\hline \multirow[t]{2}{*}{ Enalapril } & $5-20$ & $\begin{array}{l}\text { SCAT } \\
(460)\end{array}$ & 2.4 & $0.05<10.23$ & & 0.11 & $130 / 78$ & 4.0 \\
\hline & $10-20$ & $\begin{array}{l}\text { CAMELOT* } \\
\text { (1332) }\end{array}$ & 1.5 & $\frac{0.66}{\mathbf{T}_{0.71}}$ & & 0.87 & $129 / 77$ & 4.9 \\
\hline \multirow[t]{3}{*}{ Perindopril } & 4 & $\begin{array}{l}\text { PROCRESS/ } \\
\text { Mono (2561) }\end{array}$ & 12.6 & \begin{tabular}{r|}
$0.95 \mid$ \\
$\mathbf{T} 0.71$
\end{tabular} & & 0.02 & $147 / 86$ & 5.0 \\
\hline & $\begin{array}{l}4 \\
+2.5 \ln d\end{array}$ & $\begin{array}{l}\text { PROGRESS/ } \\
\text { Comb }(3544)\end{array}$ & 11.4 & $\frac{0.57}{40.57}$ & & 0.83 & $147 / 86$ & 12.0 \\
\hline & $4-8$ & $\begin{array}{l}\text { EUROPA } \\
\text { (12218) }\end{array}$ & 1.6 & T0.71 & & 0.058 & $137 / 82$ & 5.0 \\
\hline Trandolapril & $2-4$ & $\begin{array}{l}\text { PEACE } \\
(8290)\end{array}$ & 2.0 & \begin{tabular}{c|}
0.76 \\
10.82
\end{tabular} & & 0.64 & $134 / 78$ & 2.2 \\
\hline ludes TIA & & & & 0.4 & $\begin{array}{lll}1.2 & 1.4 & 1.6\end{array}$ & & & served \\
\hline
\end{tabular}

Fig. 6. Observed vs. predicted odds ratios for stroke in 5 placebo-controlled secondary prevention trials of dihydropyridine calcium-channel blockers (DHP, top) and 8 placebo-controlled secondary prevention trials of ACE inhibitors (ACEI, bottom). Predicted odds ratios were derived by meta-regression (Fig. 5). For each trial, the total number of patients analyzed and the percent of patients who experienced an event are given. $\mathrm{p}$-values are for the comparison between observed and predicted odds ratios. Acronyms of trials are defined in the Appendix. Ind., indapamide.

observed odds ratios tended to be higher than predicted $(0.88$ vs. $0.60 ; p=0.07(60))$.

Among the most recently published trials, i.e., ACTION (44, 45), INVEST (29), SHELL (30), and VALUE $(39,40)$, only ACTION $(44,45)$ (Table 4) revealed discordance between observed and predicted odds ratios for cardiovascular mortality (1.01 vs. $0.81 ; p=0.06)$, cardiovascular events $(0.94$ vs. $0.73 ; p=0.0001)$ and myocardial infarction $(1.04 v s$. $0.76 ; p=0.002)$, but not stroke $(0.78$ vs. $0.68 ; p=0.38)$. In the VALUE trial $(39,40)$, with regard to myocardial infarction, the observed outcome on valsartan was worse than predicted ( 1.19 vs. $0.98 ; p=0.03$ ), while that of amlodipine-based treatment was better than predicted from the gradient in the achieved SBP ( 0.84 vs. $1.02 ; p=0.03$; Table 4$)$. Figure 6 pro- vides detailed information on the observed and predicted odds ratios for stroke in 5 placebo-controlled secondary prevention studies of dihydropyridine calcium-channel blockers $(35,41$, $43,44,47)$ and for 8 placebo-controlled secondary intervention trials of ACE inhibitors $(41,48,49,51,54,55,57,58)$. Figure 7 gives similar information for myocardial infarction.

\section{Interpretation of the Evidence}

The main finding of our updated overview was that, by and large, reduction in SBP explained the cardiovascular outcomes in the recently published, actively controlled trials in hypertensive patients and in the placebo-controlled secondary prevention trials. On balance, the evidence suggested that 


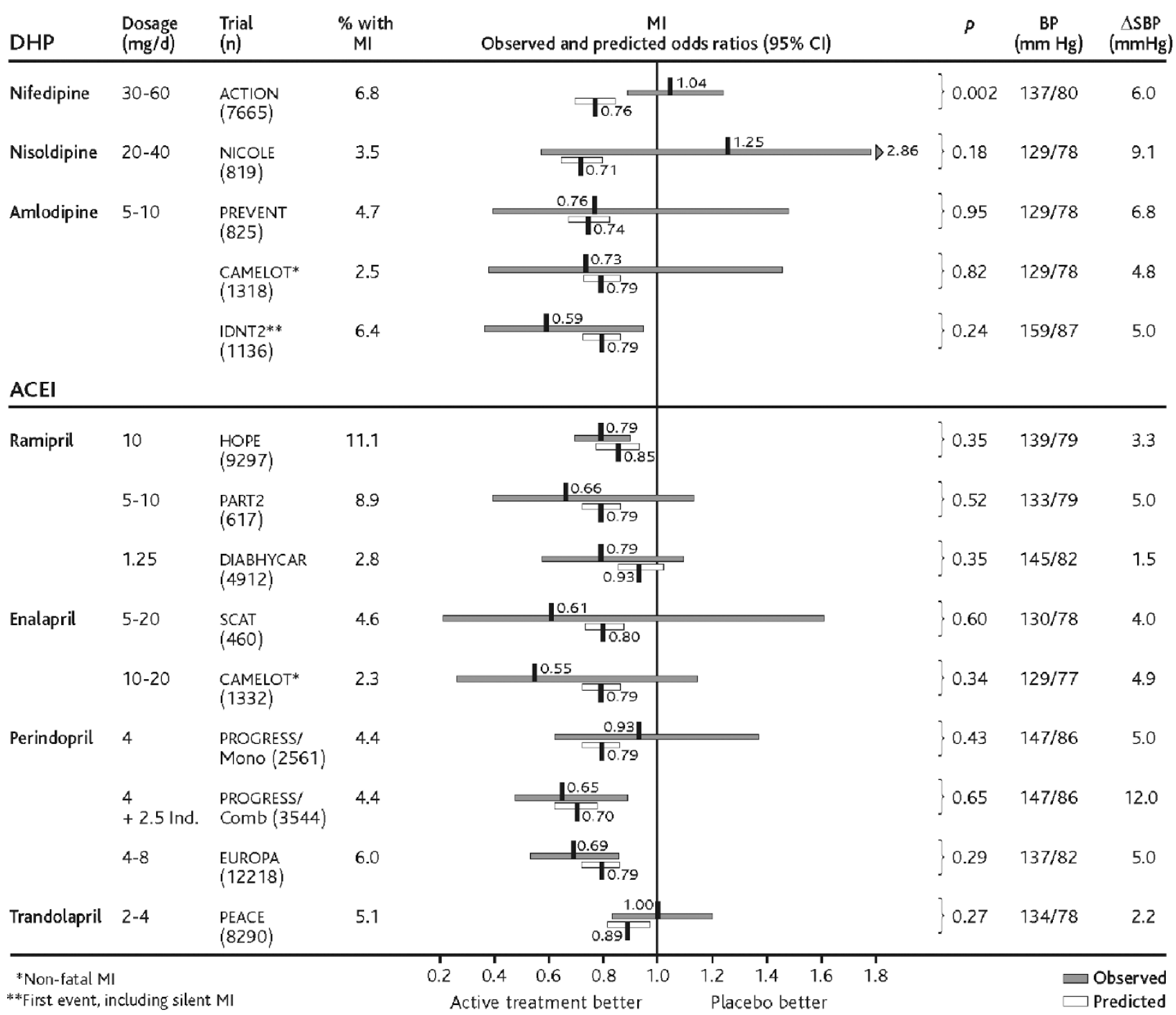

Fig. 7. Observed vs. predicted odds ratios for myocardial infarction in 5 placebo-controlled secondary prevention trials of dihydropyridine calcium-channel blockers (DHP, top) and 8 placebo-controlled secondary prevention trials of ACE inhibitors (ACEI, bottom). Predicted odds ratios were derived by meta-regression (Fig. 5). For each trial, the total number of patients analyzed and the percent of patients who experienced an event are given. p-values are for the comparison between observed and predicted odds ratios. Acronyms of trials are defined in the Appendix. Ind., indapamide.

dihydropyridine calcium-channel blockers might offer a slight but selective benefit in the prevention of stroke and inhibitors of the renin-angiotensin system in the prevention of heart failure. For prevention of myocardial infarction, the published results were more equivocal, because of the benefit of amlodipine over placebo $(35)$ or valsartan $(39,40)$ in 2 trials, whereas other placebo-controlled trials of calcium-channel blockers $(44,47)$ or ACE inhibitors $(41,54,58)$ did not substantiate the expected advantage with regard to cardiac outcomes.

\section{Prevention of Stroke}

In 2001 (5), we had already noted that calcium-channel block- ers, compared to conventional therapy with diuretics and/or $\beta$-blockers, gave $13.5 \%(p=0.03)$ greater reduction in the risk of stroke. In our 2003 review (7), we added the ALLHAT/ Aml (21), CONVINCE (19) and ELSA $(20,22)$ trials, and in our present overview we further added INVEST (29) and SHELL (30). The number of randomized patients thereby increased from 23,454 in 2001 (5) to 67,435 in 2003 (7) and 91,893 currently. Along with this addition of patients, the overall estimates of the benefit of calcium-channel blockers over old drugs in the prevention of stroke went from $7.6 \%$ $(p=0.07)$ in 2003 (7) to $8.0 \%$ in the present review $(p=0.03)$. These findings were in line with those of consecutive overviews published by the Blood Pressure-Lowering Treatment Trialists' Collaboration (111-113). In 2000 (112), starting 
from individual patient records and summary tabular data (111), this consortium reviewed 5 trials: INSIGHT (12), NICS (10), NORDIL (13), STOP2/CCBs (11), and VHAS (26). Their 2003 update (113) additionally considered AASK (31, 60, 110, 114), ALLHAT/Aml (21), CONVINCE (19), and ELSA $(20,22)$, but not INVEST (29). In these consecutive overviews, the estimates of the benefit of calcium-channel blockers over old drugs in the prevention of stroke were $13.0 \%$ (112) and 7.0\% (113), respectively. All calcium-channel blockers bind to a specific receptor domain situated on the $\alpha_{1}$-subunit of the L type calcium channel (115), but amlodipine also binds to diltiazem receptors (115). These pharmacologic characteristics, but more importantly, the low probability of heterogeneity among the trials involving dihydropyridines and diltiazem $(p=0.80)$, provided a rationale for a sensitivity analysis combining these 2 subclasses of calcium-channel blockers. After exclusion of the 2 verapamilbased trials $(28,29)$, we found a $10.0 \%(p=0.02)$ better prevention of stroke on calcium-channel blockers than old drugs.

In 2001 (5), we reviewed 3 trials comparing ACE inhibitors to conventional therapy $(9,11,16)$, which together included 16,551 randomized patients. Both treatment modalities gave similar protection against cerebrovascular accidents (5). In the present analysis, the number of relevant trials increased to $5(9,11,16,21,23)$ and the number of randomized patients rose to 46,553 . In contrast to our former findings (5), ACE inhibitors gave $10.2 \%$ less reduction in the risk of stroke than the old antihypertensive drugs. These results are in line with the secondary prevention trials in patients with a history of cerebrovascular disease, which tested inhibitors of the renin system $(51,116)$ or indapamide (84) against placebo. Neither atenolol in TEST (116) nor perindopril in the monotherapy arm of the PROGRESS trial (51) reduced the incidence of stroke recurrence, whereas in the Chinese PATS trial (84), for a similar reduction in SBP $(5.0 \mathrm{mmHg})$, indapamide decreased recurrent stroke by $29 \%$. In the EUROPA trial (49), in patients with coronary heart disease, perindopril given on top of the usual therapy did no better than placebo for the primary prevention of stroke.

In 2 trials $(23,24)$, AR1 blockers resulted in $24.4 \%$ better stroke prevention than did the old drugs, whereas the opposite trend was observed in the doxazosin arm of the ALLHAT trial $-17.5 \%, p=0.04)$. A comprehensive overview of observational cohort studies recently highlighted the fact that, throughout middle and old age, blood pressure is strongly and directly related to stroke mortality (1). Hypertension is the most consistent and powerful predictor of stroke $(1,117)$ and is involved in nearly $70 \%$ of strokes (117). It is therefore impossible to interpret the stroke results of our overview without taking into account the within-trial differences in achieved SBP (see below).

\section{Prevention of Myocardial Infarction}

We reported in $2001(5,6)$ that calcium-channel blockers, compared to diuretics and $\beta$-blockers, gave $19.2 \%$ less reduction of the risk of myocardial infarction (5). The corresponding pooled estimate reported by the Blood Pressure-Lowering Treatment Trialists' Collaboration was $12.0 \%$ (112). In the present update, the shortfall of calcium-channel blockers relative to conventional therapy disappeared in part as a result of the positive trend in favor of verapamil in CONVINCE (0.81; CI, $0.64-1.02 ; p=0.08(28))$ and the similar coronary outcomes on amlodipine and chlorthalidone in ALLHAT (0.99; CI, 0.90-1.08; $p=0.79(21))$ and on verapamil and atenolol in INVEST (1.03; CI, 0.90-1.18; $p=0.68$ (29)). Furthermore, in our previous $(5,6)$ as well as our current analysis, ACE inhibitors and old drugs performed equally well in the prevention of myocardial infarction. ANBP2 $(23,118)$ was the only actively controlled trial of ACE inhibitors, which showed a borderline significant benefit over conventional therapy in the prevention of fatal and non-fatal myocardial infarction $(0.70$; CI, $0.45-1.00 ; p=0.048)$. Thus, in the actively controlled trials, new drugs and conventional therapy prevented coronary complications to the same extent. This conclusion is supported by the observation that, for myocardial infarction, none of the $p$-values for heterogeneity reached the level of statistical significance.

Among 8 placebo-controlled secondary prevention studies $(41,48,49,51,54,55,57,58)$, ACE inhibitors reduced the risk of myocardial infarction by $20 \%$. However, among individual trials, ACE inhibition did not lead to significantly fewer myocardial infarcts in CAMELOT/En (0.55; CI, 0.26$1.15 ; p=0.11$ (41)), DIABHYCAR (0.79; CI, 0.57-1.10; $p=0.16$ (54)) and PEACE (1.00; CI, 0.83-1.20; $p>0.99$ (58)). Some investigators (58) have attributed these null results to the high frequency of background therapy with lipid-lowering drugs and anti-platelet agents. However, this explanation is unlikely because the use of such drugs was similarly high in trials that demonstrated a difference in the risk of myocardial infarction, such as EUROPA (49), or $\operatorname{VALUE}(39,40)$. More likely explanations are that either the sample size was too small to achieve significant results (41) or that the difference in SBP between randomized groups was relatively small $(54,58)$.

Among 5 placebo-controlled secondary prevention studies $(35,41,43,44,47)$, dihydropyridine calcium-channel blockers did not significantly decrease the risk of myocardial infarction. However, across the 3 trials in which amlodipine was the experimental drug, i.e., CAMELOT/Aml (41), IDNT2 (35), and PREVENT (43), amlodipine achieved a $31 \%$ higher reduction in the risk of myocardial infarction $(p=0.033)$ than placebo. These results are in line with those of the VALUE trial $(39,40)$, in which amlodipine showed a $16 \%$ greater benefit than valsartan $(p=0.02)$. These observations raise the question of whether dihydropyridine calciumchannel blockers behave as a single class for prevention of myocardial infarction. Indeed, among individual trials, point estimates tended to be higher than unity or were equal to unity for nisoldipine $v s$. enalapril in the revised $\mathrm{ABCD} / \mathrm{HT}$ results 
(3.30; CI, 1.50-7.10; $p=0.029(64)$ ), for nisoldipine vs. placebo in NICOLE (1.25; CI, 0.56-2.86; $p=0.58$ (47)), for nifedipine $v$ s. co-amilozide in INSIGHT (12) for fatal cases (3.22; CI, $1.18-8.80 ; p=0.017)$ as well as non-fatal infarcts (1.09; CI, 0.76-1.58; $p=0.52)$, for nifedipine vs. ACE inhibitors in JMIC-B (1.31; CI, 0.63-2.74; $p=0.47)$, and for nifedipine $v s$. placebo in ACTION (1.04; CI, 0.88-1.24; $p=0.62$ (44)). Differences between randomized groups in achieved SBP were small and non-significant in ABCD/HT (61) and INSIGHT (12), but favored the calcium-channel blocker in NICOLE (9.1 mmHg (47)), JMIC-B (2.0 mmHg (119)), and ACTION (6.0 mmHg (44)). Why amlodipine apparently prevented myocardial infarction more efficiently than long-acting nifedipine or nisoldipine remains to be elucidated. Several mechanisms might be involved, including the long duration of action of amlodipine, the increase in heart rate observed on nifedipine (44), the possible influence of subclinical gastrointestinal conditions on the absorption of nifedipine from a slow-release formulation, or differences between the trials in the characteristics of the randomized patients.

The results of the blood pressure-lowering limb of ASCOT (120), due to be published in 2005, might shed more light on the prevention of myocardial infarction. In a $2 \times 2$ factorial design $(120,121), 19,342$ hypertensive patients were randomized to receive amlodipine singly or in combination with perindopril or atenolol singly or in combination with bendrofluazide (open-label treatment with blinded endpoint validation), while a subgroup of 10,305 patients received double-blind treatment with either atorvastatin or placebo. The primary endpoint was the combination of death from coronary heart disease and non-fatal myocardial infarction (120, 121). Because of benefit in terms of outcome, the atorvastatin and amlodipine arms were stopped in September 2002 (121) and November 2004, respectively. The achieved blood pressure was lower on the new than on the old antihypertensive drugs. An interaction between blood pressure and lipid lowering might therefore have contributed to the immediate separation of the Kaplan-Meier estimates in the lipid trial (121).

\section{Prevention of Heart Failure}

The risk of heart failure was higher on calcium-channel blockers than on conventional therapy without heterogeneity among the trials. In individual studies, the risk of heart failure was significantly increased on nifedipine GITS in INSIGHT (2.18; CI, 1.06-2.18; $p=0.03$ (12)), on amlodipine in ALLHAT (1.38; CI, $1.25-1.50 ; p<0.001(21)$ ), and on verapamil in CONVINCE (odds ratio 1.30; CI, 1.00-1.69; $p=0.05$ (19)). Calcium-channel blockers reduce left ventricular afterload. However, neuro-endocrine activation in response to arterial vasodilatation, as exemplified by the increase in heart rate induced by nifedipine in the ACTION trial (44), as well as the direct negative inotropic action on the myocardium, may elicit heart failure in predisposed patients (122). Nevertheless, on top of diuretics and/or ACE inhibitors, long-acting dihydropyridines $(123,124)$, diltiazem $(125)$ and verapamil (126) can be used in patients with left ventricular dysfunction to lower blood pressure or to treat angina pectoris. The reduction of heart failure on nifedipine GITS vs. placebo in ACTION (0.71; CI, 0.54-0.94; $p=0.015$ (44)) was unexpected, but may have been due to the $6.0 \mathrm{mmHg}$ lower SBP in the patients on nifedipine or to unbalanced prescription of background medications in favor of the actively treated patients. The ACTION report (44), similarly to several other studies $(54,55,58)$, did not provide any information on concomitant medications after randomization.

Among the trials of new vs. old drugs (7), all newer agents on average performed $23.1 \%$ worse in the prevention of heart failure than conventional therapy. This is not surprising, because both diuretics and $\beta$-blockers belong to the standard of care (127). The same is true for ACE inhibitors given on top of digitalis and diuretics. AR1 blockers, perhaps with the exception of candesartan titrated up to $32 \mathrm{mg}$ daily (128131), are only indicated as alternatives to ACE inhibitors when class-specific side-effects, such as cough, occur (127, 132-134). Two trials of the combination of ACE inhibitors and AR1 blockers in patients with heart failure reported contradictory results $(130,135)$.

The higher risk of heart failure on lisinopril in ALLHAT (1.19; CI, 1.07-1.31; $p<0.001$ (21)) is counterintuitive, whereas the results of the ALLHAT doxazosin arm (1.80; CI, $1.61-2.02 ; p<0.001(14,32))$ were in line with previous studies (136). In trials of ACE inhibitors in patients with heart failure (127) or high cardiovascular risk $(51,55)$, these agents were always combined with diuretics. In contrast to current guidelines $(3,137)$, in therapy-resistant ALLHAT patients, lisinopril had to be used in combination with sympatholytic agents and/or hydralazine before diuretics could be added (21). Furthermore, heart failure in ALLHAT was only a component of a secondary endpoint, which did not lead to an increase in cardiovascular $(21)$ or total $(14,21)$ mortality. At randomization, $90.2 \%$ of the ALLHAT patients were already on antihypertensive drugs, diuretics in most cases. Thus, the patients allocated to receive amlodipine, lisinopril or doxazosin were at risk of rapidly losing the protection conferred by their previous diuretic treatment, whereas in those of the chlorthalidone group the volume-dependent signs and symptoms of heart failure remained suppressed. These design features of ALLHAT likely explain why the Kaplan-Meier estimates for heart failure separated immediately after randomization $(14,21,32)$. Because of the weight of ALLHAT in our overview, pooled estimates including this trial must be cautiously interpreted.

In the main analysis of the VALUE trial (39), the risk of heart failure was slightly less on valsartan than amlodipine (0.89; CI, $0.77-1.03 ; p=0.12)$. This trend reached borderline significance in 2 post-hoc analyses $(39,40)$. First, the VALUE investigators artificially subdivided the follow-up period into consecutive intervals characterized by progressively decreasing between-group differences in SBP (39). In 
the interval from 36 to 48 months the risk was 0.69 (CI, 0.510.94). However, these time-interval-specific analyses were biased for all periods but the first ( $0-3$ months), because event rates in each sequential period were conditional on those occurring earlier $(39,40)$. Patients continuing to each subsequent period were therefore unbalanced with regard to risk and randomization. Second, in an accompanying paper (40), the VALUE consortium performed serial median matching using the SBP level at 6 months and found that the risk of heart failure on valsartan $v s$. amlodipine was 0.81 (CI, 0.66$0.99 ; p=0.04)$. This matched-pair approach (40) accounted for the attained SBP (within $2 \mathrm{mmHg}$ ) and other cardiovascular risk factors, but excluded 5,233 patients (34.3\%) whose SBP was too high on valsartan or too low on amlodipine to allow matching.

\section{Role of Blood Pressure Reduction}

Until the turn of the millennium, the consensus interpretation of the evidence produced by the outcome trials in hypertensive patients $(8-16,27,28,48,51,57,75-88,90-96,106$, 138 ) was that blood pressure is a risk factor amenable to intervention, with lower levels entailing fewer complications. However, the HOPE trial $(55,56)$ gave rise to the hypothesis that ACE inhibitors might reduce cardiovascular complications beyond blood pressure control. Subsequently, trials of AR1 blockers in hypertensive patients with renal failure (33, $69,71)$ or left ventricular hypertrophy $(17,18)$ as well as several secondary prevention trials of ACE inhibitors $(35,49,54$, 58 ) or AR1 blockers (39) sought to reinforce this hypothesis.

Our previous meta-regression analyses (5-7) along with the present overview in total considered 45 trials $(8-14,16-$ $21,23-25,27,29,30,32-35,39,40,43,44,46-48,51,54-$ $57,59,71,74-77,79-84,86-96,109,119)$. Several of these trials involved multiple comparisons of various active drugs with placebo or with each other. From each trial and for each comparison, we tried to extract information on cardiovascular mortality, cardiovascular morbidity, stroke and myocardial infarction. A substantial number of the reviewed trials (18$21,23-25,29,30,35,39,41,43,44,47,49,51,54,58,60$, 65 ) announced their results after 2001, when we had first published our meta-regression models (5). To standardize our analysis, we did not use adjusted relative risks as published in many articles. Instead, we recalculated the observed odds ratios from the number of events and the number of patients per group randomized in each trial by use of $2 \times 2$ contingency tables (5). Across all reviewed trials and endpoints, only in 14 instances did we find a significant or borderline significant difference between observed and predicted odds ratios. These findings underscore that the outcome results of most trials in patients with hypertension or high cardiovascular risk should be attributed to the within-trial differences in SBP. This point of view is also in line with the evidence from observational, prospective studies. Indeed, in middle-aged and older patients, SBP is the prevailing blood pressure com- ponent with regard to cardiovascular prognosis $(139,140)$. In a quantitative overview involving one million subjects, the Prospective Studies Collaboration demonstrated that small gradients in blood pressure similar to those observed in recent trials might account for substantial differences in cardiovascular outcomes (1).

For myocardial infarction (0.70 vs. 1.08) in the ANBP2 trial (23), and hence for all cardiovascular events (0.90 vs. $1.15)$, the odds ratios for therapy with ACE inhibitors $v s$. conventional therapy were significantly lower than those predicted by the achieved SBP, which was $2.0 \mathrm{mmHg}$ higher in the patients on ACE inhibitors. Similar trends were also observed for myocardial infarction in the lisinopril arm of the ALLHAT trial (21), both in all patients (0.98 vs. 1.14) and in those aged 65 years or more (1.01 vs. 1.20), whose SBP was 2.3 and $3.0 \mathrm{mmHg}$ higher, respectively, than in the corresponding controls randomized to receive chlorthalidone. Thus, if one considers the achieved SBP, ACE inhibitors in Caucasian hypertensive patients seem to offer a slightly greater protection against coronary complications than conventional therapy. These findings are in line with the secondary prevention trials in patients with acute myocardial infarction $(141,142)$. CAMELOT (41) and PEACE (58) only reported the incidence of non-fatal myocardial infarction, which in the context of the endpoint definitions used in the present overview does not facilitate the interpretation in relation to blood pressure.

The achieved SBP levels and associated stroke rates in the lisinopril arm of the ALLHAT trial (21) corroborated the concept that older and black patients usually have a low-renin volume-expanded type of hypertension, which responds better to initial treatment with diuretics or calcium-channel blockers (143-146). In 2 trials comparing AR1 blockers (18, 24 ) with conventional therapy, the realization of lower SBP explained the better outcomes on losartan $(17,18)$ or candesartan (147). Both trials had a double-blind design, but they were also characterized by the more frequent discontinuation of the double-blind study medication in the control group (18, $147)$ and the more frequent use of open-label drugs either in the experimental (18) or in the control (147) group. The systolic gradient was larger in SCOPE (147) than in LIFE (17, 18 ), but the $p$-value for heterogeneity in the stroke outcomes between these 2 trials was non-significant. Thus, as discussed elsewhere (148), our present findings are at variance with the LIFE investigators' interpretation that claimed benefit beyond blood pressure control for losartan vs. atenolol (17, 18). To what extent unopposed stimulation of type 2 angiotensin II receptors in the brain contributes to the divergent stroke outcomes on ACE inhibitors and AR1 receptor blockers relative to conventional therapy remains to be elucidated (149).

Two instances in which there was a significant deviation between observed and predicted odds ratios highlight the need for further research. First, in the pilot run of the HYVET trial (25), active treatment compared to no intervention low- 
ered SBP by $22.5 \mathrm{mmHg}$, but did not reduce cardiovascular mortality. The observed and predicted odds ratios were 1.19 $v s$. 0.55 , respectively. Second, in the AASK trial $(31,60)$, intensive blood pressure lowering compared to conventional care led to a $16.0 \mathrm{mmHg}$ difference in SBP with less reduction in the cardiovascular event rate than expected (odds ratios, 0.88 vs. 0.60).

We did not compute a meta-regression line for heart failure, because among the 30 trials in our 2001 overview (5) only 13 reported on this endpoint and because the criteria for its diagnosis were not standardized across trials. In their 2003 report (113), the Blood Pressure Lowering Treatment Trialists' Collaboration observed that for every outcome other than heart failure, the differences between randomized groups in cardiovascular outcomes were directly related to the achieved SBP. However, the lack of association for heart failure was mainly due to 4 trials, i.e., IDNT2 (33-35), NICOLE $(46,47)$, PREVENT $(42,43)$ and Syst-Eur (81-83), which compared calcium-channel blockers to placebo. The question remains whether from a clinical point of view the pooled results of one primary prevention trial in older patients with isolated systolic hypertension (81) and of 3 secondary prevention studies in diabetic patients with renal dysfunction (35) or in high-risk patients with coronary heart disease $(43,47)$ can be usefully interpreted. Indeed, there are substantial differences in the pathophysiologic mechanisms causing left ventricular failure in such heterogeneous patient groups $(150,151)$.

\section{Conclusions}

Most trials published over the past decade have enrolled primarily middle-aged and older patients of male sex at high cardiovascular risk, who had previous complications, associated diseases, or both. To what extent their findings can be reasonably extrapolated to younger and female patients in a routine clinical setting remains a matter of concern (152).

The hypothesis that new antihypertensive drugs, such as calcium-channel blockers, $\alpha$-blockers, ACE inhibitors or AR1 blockers, might influence cardiovascular prognosis over and beyond their antihypertensive effect remains unproven. In the primary and secondary prevention trials of blood pressure-lowering drugs, the achieved SBP was the major determinant of cardiovascular outcome. This observation is in keeping with the recent findings in Syst-Eur (153) and VALUE $(39,40)$, which highlighted that immediate blood pressure lowering and early blood pressure control are key determinants of cardiovascular prognosis. Although a number of secondary prevention trials included normotensive patients, the level to which blood pressure must be lowered to achieve maximal benefit remains to be clarified.

The relevance of achieved blood pressure for cardiovascular prognosis must be gauged in terms of the poor control rates of SBP in the population at large (154) as well as in primary care (155). If blood pressure is the major determinant of prognosis, the inescapable inference is that antihypertensive therapy should be individualized and initiated with the drug class that is most likely to be effective in each individual patient, taking into account his overall risk profile and comorbid conditions (3). In over $60 \%$ of patients, optimization of treatment at acceptable levels of tolerance requires rotation through and combination of several drug classes. The blood pressure-lowering activities of ACE inhibitors and $\beta$-blockers are additive to those of thiazides and calcium-channel blockers and vice-versa $(145,146)$. Patients younger than 50 years may be started on ACE inhibitors or $\beta$-blockers and switched to combination therapy with either thiazides or calcium-channel blockers if blood pressure remains uncontrolled, whereas older patients may proceed in the reverse order $(145,146)$. Because most patients need combination therapy to achieve blood pressure control, the debate which drug class is best suited to start antihypertensive treatment is largely elusive.

\section{Acknowledgements}

The authors gratefully acknowledge the secretarial assistance of Miss Sandra Covens and Mrs. Renilde Wolfs.

\section{Appendix}

\section{Acronyms of Trials}

AASK, the African American Study of Kidney disease and hypertension $(31,60,110,114)$; ABCD, Appropriate Blood Pressure Control in Diabetes trial (61-65); ABCD/HT, Appropriate Blood Pressure Control in Diabetes trial - nisoldipine vs. enalapril in hypertensive patients $(61,63,64)$; $\mathrm{ABCD} / \mathrm{NT}$, Appropriate Blood Pressure Control in Diabetes trial-tight vs. usual blood pressure control in normotensive patients (65); ACTION, A Coronary disease Trial Investigating Outcome with Nifedipine GITS $(44,45)$; ALLHAT, Antihypertensive and Lipid-Lowering Treatment to Prevent Heart Attack Trial (21); ALLHAT/Aml, Antihypertensive and Lipid-Lowering Treatment to Prevent Heart Attack Trial—amlodipine vs. chlorthalidone (21); ALLHAT/Dox, Antihypertensive and Lipid-Lowering Treatment to Prevent Heart Attack Trial-doxazosin vs. chlorthalidone (14, 32); ALLHAT/Lis, Antihypertensive and Lipid-Lowering Treatment to Prevent Heart Attack Tria!-lisinopril vs. chlorthalidone (21); ANBP2, Australian comparative outcome trial of angiotensin-converting enzyme inhibitor- and diuretic-based treatment of hypertension in the elderly (23); ASCOT, the Anglo-Scandinavian Cardiac Outcomes Trial (120, 121); ATMH, Australian Trial in Mild Hypertension (87); BENEDICT, BErgamo NEphrologic DIabetes Complications Trial $(66,67)$; CAMELOT, Comparison of AMlodipine $v$ s. Enalapril to Limit Occurrences of Thrombosis (41); CAMELOT/Aml, Comparison of AMlodipine vs. Enalapril to Limit Occurrences of Thrombosis-amlodipine vs. placebo (41); CAMELOT/En, Comparison of AMlodipine vs. Enalapril to Limit Occurrences of Thrombosis_enalapril $v s$. placebo (41); CASTEL, CArdiovascular STudy in the ELderly (104); CALM, CAndesartan and Lisinopril Microalbuminuria study (68); CONVINCE, Controlled ONset Verapamil INvestigation of Cardiovascular Endpoints trial (19); CAPPP, Captopril Prevention Project $(9,73)$; CONVINCE, Controlled ONset Ver- 
apamil INvestigation of Cardiovascular Endpoints trial (19); DIABHYCAR, the non-insulin-dependent DIABetes, HYpertension, microalbuminuria or proteinuria, CArdiovascular events, and Ramipril study (52-54); ELSA, European Lacidipine Study on Atherosclerosis $(20,22)$; EUROPA, EURopean trial On reduction of cardiac events with Perindopril in stable coronary Artery disease (49); EWPHE, trial conducted by the European Working Party on High Blood Pressure in the Elderly $(88,89)$; HEP, trial of Hypertension in Elderly Patients in primary care (86); HDFP, Hypertension Detection and Follow-Up Program $(102,103)$; HOPE, Heart Outcomes Prevention Evaluation study $(55,56)$; HOT, Hypertension Optimal Treatment trial (76); HOT/ LH, Hypertension Optimal Treatment trial (76)—80 vs. 90 $\mathrm{mmHg}$ as target diastolic pressure); HOT/MH, Hypertension Optimal Treatment trial (76)-85 vs. $90 \mathrm{mmHg}$ as target diastolic pressure); HYVET, HYpertension in the Very Elderly Trial pilot study (25); HYVET/AD, HYpertension in the Very Elderly Trial pilot study-ACE inhibition $v s$. diuretic treatment (25); HYVET/ BP, HYpertension in the Very Elderly Trial pilot study—blood pressure lowering drugs vs. no treatment (25); IDNT2, Irbesartan Diabetic Nephropathy Trial in patients with type 2 diabetes mellitus (33-35); INSIGHT, International Nifedipine GITS Study-Intervention as a Goal for Hypertension Therapy (12, 74); IRMA2, IRbesartan in patients with type 2 diabetes and MicroAlbuminuria study (69); INVEST, INternational VErapamil SR/trandolapril STudy (29); JMIC-B, the Japan Multicenter Investigation for Cardiovascular diseases-B (119); LIFE, Losartan Intervention For Endpoint reduction in hypertension study $(17,18,106,107)$; LIFE/All, Losartan Intervention For Endpoint reduction in hypertension study - all patients (18); LIFE/DM, Losartan Intervention For Endpoint reduction in hypertension study — diabetic subgroup (17); HSCS, Hypertension-Stroke Cooperative Study (90); MIDAS, Multicenter Isradipine Diuretic Atherosclerosis Study (8); MIDAS/NICS/VHAS, combined results of MIDAS (8), NICS (10) and VHAS (15); MRC1, Medical Research Council trial of treatment of mild hypertension (91); MRC2, Medical Research Council trial of treatment of hypertension in older adults (92); NICOLE, NIsoldipine in COronary artery disease in LEuven $(46,47)$; NICS, National Intervention Cooperative Study in elderly hypertensives (10); NORDIL, NORdic DILtiazem study (13); OSLO, Oslo Study on the Treatment of Mild Hypertension (27); PART2, Prevention of Atherosclerosis with Ramipril Trial (57); PART2/ SCAT, combined results of PART2 (57) and SCAT (48); PATS, Post-stroke Antihypertensive Treatment Study (84); PEACE, Prevention of Events with Angiotensin Converting Enzyme inhibition (58); PREVENT, Prospective Randomized Evaluation of the Vascular Effects Norvasc Trial $(42,43)$; PROGRESS, Perindopril PrOtection aGainst Recurrent Stroke Study (51, 59, 85); PROGRESS/Com, Perindopril PrOtection aGainst Recurrent Stroke Study (51, 59, 85)-group on combined therapy); PROGRESS/Per, Perindopril PrOtection aGainst Recurrent Stroke Study $(51,59,85)$-group on single-drug treatment; REIN, Ramipril Efficacy In Nephropathy trial (70); RENAAL, Reduction of Endpoints in NIDDM with the Angiotensin II Antagonist Losartan (71); RCT70-80, combined results of 4 smaller trials published from 1970 through 1980, including HSCS (90), OSLO (27), USPHS (95), and VACS (96); SCAT, Simvastatin/enalapril Coronary Atherosclerosis Trial (48); SCOPE, Study on COgnition and Prognosis in the Elderly (24,
108, 109); SHELL, Systolic Hypertension in the Elderly Longterm Lacidipine trial (30); SHEP, Systolic Hypertension in the Elderly Program (77, 78); STONE, Shanghai Trial of Nifedipine in the Elderly (94); STOP1, Swedish Trial in Old Patients with hypertension (93); STOP2, Swedish Trial in Old Patients with hypertension-2 (11); STOP2/ACEIs, angiotensin-converting enzyme inhibitor arm of STOP2 (11); STOP2/CCBs, calciumchannel blocker arm of STOP2 (11); Syst-China, Systolic Hypertension in China Trial $(79,80)$; Syst-Eur, Systolic Hypertension in Europe Trial (81-83); TEST, TEnormin after Stroke and TIA (116); UKPDS, UKPDS Hypertension in Diabetes Study (16, 75); UKPDS/CA, UKPDS Hypertension in Diabetes Studycaptopril $v s$. atenolol (16); UKPDS/LH, UKPDS Hypertension in Diabetes Study-low vs. high on-treatment blood pressure (75); USPHS, United States Public Health Service Hospitals Cooperative Study (95); VACS, Veterans Administration Cooperative Study in patients with diastolic blood pressure averaging 90-114 mmHg (96); VALUE, Valsartan Antihypertensive Long-term Use Evaluation (36-40); VHAS, Verapamil in Hypertension and Atherosclerosis Study (26)

\section{References}

1. Prospective Studies Collaboration: Age-specific relevance of usual blood pressure to vascular mortality: a meta-analysis of individual data for one million adults in 61 prospective studies. Lancet 2002; 360: 1903-1913.

2. Asia Pacific Cohort Studies Collaboration: Blood pressure and cardiovascular disease in the Asia Pacific region. $J$ Hypertens 2003; 21: 707-716.

3. European Society of Hypertension/European Society of Cardiology Guidelines Committee: 2003 European Society of Hypertension/European Society of Cardiology guidelines for the management of arterial hypertension. J Hypertens 2003; 21: 1011-1053.

4. Chobanian AV, Bakris GL, Black BK, et al: The seventh report of the Joint National Committee on Prevention, Detection, Evaluation, and Treatment of High Blood Pressure. The JNC 7 Report. JAMA 2003; 289: 2560-2572.

5. Staessen JA, Wang JG, Thijs L: Cardiovascular prevention and blood pressure reduction: a meta-analysis. Lancet 2001; 358: 1305-1315 (erratum published in Lancet 2002; 359: $360)$.

6. Staessen JA, Wang JG, Thijs L: Calcium-channel blockade and cardiovascular prognosis: recent evidence from clinical outcome trials. Am J Hypertens 2002; 15: 85S-93S.

7. Staessen JA, Wang JG, Thijs L: Cardiovascular prevention and blood pressure reduction: a quantitative overview updated until March 2003. J Hypertens 2003; 21: 10551076.

8. Borhani NO, Mercuri M, Borhani PA, et al: Final outcome results of the multicenter isradipine diuretic atherosclerosis study (MIDAS). A randomized controlled trial. JAMA 1996; 276: 785-791.

9. Hansson L, Lindholm LH, Niskanen L, et al: Effect of angiotensin-converting-enzyme inhibition compared with conventional therapy on cardiovascular morbidity and mortality in hypertension: the Captopril Prevention Project (CAPPP) randomised trial. Lancet 1999; 353: 611-616.

10. National Intervention Cooperative Study in Elderly Hyper- 
tensives Study Group: Randomized double-blind comparison of a calcium antagonist and a diuretic in elderly hypertensives. Hypertension 1999; 34: 1129-1133.

11. Hansson L, Lindholm LH, Ekbom T, et al: Randomised trial of old and new antihypertensive drugs in elderly patients: cardiovascular mortality and morbidity in the Swedish Trial in Old Patients with Hypertension-2 study. Lancet 1999; 354: 1751-1756.

12. Brown MJ, Palmer CR, Castaigne A, et al: Morbidity and mortality in patients randomised to double-blind treatment with long-acting calcium-channel blocker or diuretic in the International Nifedipine GITS Study: Intervention as a Goal in Hypertensive Treatment (INSIGHT). Lancet 2000; 356: 366-372.

13. Hansson L, Hedner T, Lund-Johansen P, et al: Randomised trial of effects of calcium antagonists compared with diuretics and $\beta$-blockers on cardiovascular morbidity and mortality in hypertension: the Nordic Diltiazem (NORDIL) study. Lancet 2000; 356: 359-365.

14. The ALLHAT Officers and Coordinators for the ALLHAT Collaborative Research Group: Major cardiovascular events in hypertensive patients randomized to doxazosin $v s$ chlorthalidone. The Antihypertensive and Lipid-Lowering Treatment to Prevent Heart Attack Trial (ALLHAT). JAMA 2000; 283: 1967-1975.

15. Agabiti Rosei E, Dal Palú C, Leonetti G, et al: Clinical results of the Verapamil in Hypertension and Atherosclerosis Study. J Hypertens 1997; 15: 1337-1344.

16. UK Prospective Diabetes Study Group: Efficacy of atenolol and captopril in reducing risk of macrovascular and microvascular complications in type 2 diabetes: UKPDS 39. BMJ 2000; 317: 713-720.

17. Lindholm LH, Ibsen H, Dahlöf B, et al: Cardiovascular morbidity and mortality in patients with diabetes in the Losartan Intervention For Endpoint reduction in hypertension study (LIFE): a randomised trial against atenolol. Lancet 2002; 359: 1004-1010.

18. Dahlöf B, Devereux RB, Kjeldsen SE, et al: Cardiovascular morbidity and mortality in the Losartan Intervention For Endpoint reduction in hypertension study (LIFE): a randomised trial against atenolol. Lancet 2002; 359: 995-1003.

19. Black HR, Elliott WJ, Grambsch P, et al: Principal results of the Controlled ONset Verapamil INvestigation of Cardiovascular Endpoints (CONVINCE) Trial. JAMA 2003; 289: 2073-2082.

20. Zanchetti A, Bond G, Hennig M, et al: Calcium antagonist lacidipine slows down progression of asymptomatic carotid atherosclerosis. Principal results of the European Lacidipine Study on Atherosclerosis (ELSA), a randomized, doubleblind, long-term trial. Circulation 2002; 106: 2422-2427.

21. The ALLHAT Officers and Coordinators for the ALLHAT Collaborative Research Group: Major outcomes in high-risk hypertensive patients randomized to angiotensin-converting enzyme inhibitor or calcium channel blocker vs. diuretic. The Antihypertensive and Lipid-Lowering Treatment to Prevent Heart Attack Trial (ALLHAT). JAMA 2002; 288: 2981-2997.

22. Zanchetti A, Bond MG, Hennig M, et al: Risk factors associated with alterations in carotid intima-media thickness in hypertension: baseline data from the European Lacidipine
Study on Atherosclerosis. J Hypertens 1998; 16: 949-961.

23. Wing LMH, Reid CM, Ryan P, et al: A comparison of outcomes with angiotensin-converting-enzyme inhibitors and diuretics for hypertension in the elderly. $N$ Engl $\mathrm{J} \mathrm{Med}$ 2003; 348: 583-592.

24. Lithell H, Hansson L, Skoog I, et al: The study on cognition and prognosis in the elderly (SCOPE). Principal results of a randomised double-blind intervention trial. $J$ Hypertens 2003; 21: 875-886.

25. Bulpitt CJ, Beckett NS, Cooke J, et al: Results of the pilot study for the Hypertension in the Very Elderly Trial. $J$ Hypertens 2003; 21: 2409-2417.

26. Zanchetti A, Agabiti Rosei E, Dal Palú C, et al: The Verapamil in Hypertension and Atherosclerosis Study (VHAS): results of long-term randomized treatment with either verapamil or chlorthalidone on carotid intima-media thickness. J Hypertens 1998; 16: 1667-1676.

27. Helgeland A: Treatment of mild hypertension: a five year controlled drug trial. Am J Med 1980; 69: 725-732.

28. Black HR, Elliott WJ, Neaton JD, et al: Baseline characteristics and early blood pressure control in the CONVINCE trial. Hypertension 2001; 37: 12-18.

29. Pepine CJ, Handberg EM, Cooper-DeHoff RM, et al: A calcium antagonist $v s$ a non-calcium antagonist hypertension treatment strategy for patients with coronary heart disease. The International Verapamil-Trandolapril Study (INVEST): a randomized controlled trial. JAMA 2003; 290: 28052816.

30. Malacco E, Mancia G, Rappelli A, et al: Treatment of isolated systolic hypertension: the SHELL study results. Blood Press 2003; 12: 160-167.

31. Agodoa LY, Appel L, Bakris GL, et al: Effect of ramipril vs amlodipine on renal outcomes in hypertensive nephrosclerosis. JAMA 2001; 285: 2719-2728.

32. ALLHAT Officers and Coordinators for the ALLHAT Collaborative Research Group: Diuretic versus $\alpha$-blocker as first step antihypertensive therapy. Final results from the Antihypertensive and Lipid-Lowering Treatment to Prevent Heart Attack Trial (ALLHAT). Hypertension 2003; 42: 239-246.

33. Lewis EJ, Hunsicker LG, Clarke WR, et al: Renoprotective effect of the angiotensin-receptor antagonist irbesartan in patients with nephropathy due to type 2 diabetes. $N$ Engl $J$ Med 2001; 345: 851-860.

34. Rodby RA, Rohde RD, Clarke WR, et al: The Irbesartan Type II Diabetic Nephropathy Trial: study design and baseline patient characteristics. Nephrol Dial Transplant 2000; 15: 487-497.

35. Berl T, Hunsicker LG, Lewis JB, et al: Cardiovascular outcomes in the Irbesartan Diabetic Nephropathy Trial of patients with type 2 diabetes and overt nephropathy. Arch Intern Med 2003; 138: 542-549.

36. Julius S, Kjeldsen SE, Brunner H, et al: VALUE Trial: long-term blood pressure trends in 13,449 patients with hypertension and high cardiovascular risk. Am J Hypertens 2003; 16: 544-548.

37. Mann J, Julius S, for the VALUE Trial Group: The Valsartan Antihypertensive Long-term Use Evaluation (VALUE) Trial of cardiovascular events in hypertension. Rationale and design. Blood Press 1998; 7: 176-183. 
38. Kjeldsen SE, Julius S, Brunner H, et al: Characteristics of 15314 hypertensive patients at high coronary risk. The VALUE Trial. Blood Press 2001; 10: 83-91.

39. Julius S, Kjeldsen SE, Weber M, et al: Outcomes in hypertensive patients at high cardiovascular risk treated with valsartan- or amlodipine-based regimens: VALUE, a randomised trial. Lancet 2004; 363: 2022-2031.

40. Weber MA, Julius S, Kjeldsen SE, et al: Blood pressure dependent and independent effects of antihypertensive treatment on clinical events in the VALUE Trial. Lancet 2004; 363: 2049-2051.

41. Nissen SE, Tuzcu EM, Libby P, et al: Effect of antihypertensive agents on cardiovascular events in patients with coronary heart disease and normal blood pressure. The CAMELOT study: a randomized controlled trial. JAMA 2004; 292: 2217-2226.

42. Byington RB, Miller ME, Herrington D, et al: Rationale, design, and baseline characteristics of the Prospective Randomized Evaluation of the Vascular Effects of Norvasc Trial (PREVENT). Am J Cardiol 1997; 80: 1087-1090.

43. Pitt B, Byington RP, Furberg CD, et al: Effect of amlodipine on the progression of atherosclerosis and the occurrence of clinical events. Circulation 2000; 102: 1503-1510.

44. Poole-Wilson PA, Lubsen J, Kirwan BA, et al: Effect of long-acting nifedipine on mortality and cardiovascular morbidity in patients with stable angina requiring treatment (ACTION trial): randomised controlled trial. Lancet 2004; 364: 849-857.

45. Lubsen J, Poole-Wilson PA, Pocock SJ, et al: Design and current status of ACTION: A Coronary disease Trial Investigating Outcome with Nifedipine GITS. Eur Heart J 1998; 19 (Suppl I): I20-I32.

46. Dens JA, Desmet WJ, Coussement P, et al: Usefulness of nisoldipine for prevention of restenosis after percutaneous transluminal coronary angioplasty (results of the NICOLE study). NIsoldipine in COronary artery disease in LEuven. Am J Cardiol 2001; 87: 28-33.

47. Dens JA, Desmet WJ, Coussement P, et al: Long term effects of nisoldipine on the progression of coronary atherosclerosis and the occurrence of clinical events: the NICOLE study. Heart 2003; 89: 887-892.

48. Teo KK, Burton JR, Buller CE, et al: Long-term effects of cholesterol lowering and angiotensin-converting enzyme inhibition on coronary atherosclerosis. The Simvastatin/ Enalapril Coronary Atherosclerosis Trial (SCAT). Circulation 2000; 102: 1748-1754.

49. The European Trial on Reduction of Cardiac Events with Perindopril in Stable Coronary Artery Disease Investigators: Efficacy of perindopril in reduction of cardiovascular events among patients with stable coronary heart disease: randomised double-blind, placebo-controlled, multicentre trial (the EUROPA study). Lancet 2003; 362: 782-788.

50. Neal B, MacMahon S, on behalf of the PROGRESS Management Committee: The PROGRESS study: rationale and design. J Hypertens 1995; 13: 1869-1873.

51. PROGRESS Collaborative Group: Randomised trial of a perindopril-based blood pressure lowering regimen among 6105 individuals with prior stroke or transient ischaemic attack. Lancet 2001; 358: 1033-1041.

52. Lièvre M, Marre M, Chatellier G, et al: The non-insulin- dependent diabetes, hypertension, microalbuminuria or proteinuria, cardiovascular events, and ramipril (DIABHYCAR) study: design, organization, and patient recruitment. Control Clin Trials 2000; 21: 383-396.

53. Marre M, Lièvre M, Vasmant $\mathrm{D}$, et al: Determinants of elevated urinary albumin in the 4,937 type 2 diabetic subjects recruited for the DIABHYCAR study in Western Europe and Northern Africa. Diabet Care 2000; 23 (Suppl 2): B40B48.

54. Marre M, Lievre M, Chatellier G, et al: Effects of low dose ramipril on cardiovascular and renal outcomes in patients with type 2 diabetes and raised excretion of urinary albumin: randomised, double blind, placebo controlled trial (the DIABHYCAR study). BMJ 2004; 328: 495-501 (erratum published in $B M J$ 2004; 328: 686).

55. The Heart Outcomes Prevention Evaluation Study Investigators: Effects of an angiotensin-converting-enzyme inhibitor, ramipril, on cardiovascular events in high-risk patients. N Engl J Med 2000; 342: 145-153.

56. Heart Outcomes Prevention Evaluation Study Investigators: Effects of ramipril on cardiovascular and microvascular outcomes in people with diabetes mellitus: results of the HOPE study and MICRO-HOPE substudy. Lancet 2000; 355: 253-259.

57. MacMahon S, Sharpe N, Gamble G, et al: Randomized, placebo-controlled trial of the angiotensin-converting enzyme inhibitor, ramipril, in patients with coronary or other occlusive arterial disease. J Am Coll Cardiol 2000; 36: 438-443.

58. The PEACE Trial Investigators: Angiotensin-convertingenzyme inhibition in stable coronary heart artery disease. $N$ Engl J Med 2004; 351: 2058-2068.

59. PROGRESS Collaborative Group: Effects of perindoprilbased blood pressure lowering regimen on cardiac outcomes among patients with cerebrovascular disease. Eur Heart J 2003; 24: 475-484.

60. Wright JT Jr, Bakris G, Greene T, et al: Effect of blood pressure lowering and antihypertensive drug class on progression of hypertensive kidney disease. Results from the AASK trial. JAMA 2002; 288: 2421-2431.

61. Estacio RO, Jeffers BW, Hiatt WR, Biggerstaff SL, Gifford N, Schrier RW: The effect of nisoldipine as compared with enalapril on cardiovascular outcomes in patients with noninsulin-dependent diabetes and hypertension. $N$ Engl J Med 1998; 338: 645-652.

62. Estacio RO, Savage S, Nagel NJ, Schrier RW: Baseline characteristics of participants in the Appropriate Blood Pressure Control in Diabetes trial. Control Clin Trials 1996; 17: 242-257.

63. Estacio RO, Jeffers BW, Gifford N, Schrier RW: Effect of blood pressure control on diabetic microvascular complications in patients with hypertension and type 2 diabetes. Diabet Care 2000; 23 (Suppl 2): B54-B64.

64. Schrier RW, Estacio RO: Additional follow-up from the ABCD trial in patients with type 2 diabetes and hypertension. N Engl J Med 2000; 343: 1969.

65. Schrier RW, Estacio RO, Esler A, Mehler P: Effects of aggressive blood pressure control in normotensive type 2 diabetic patients on albuminuria, retinopathy and strokes. Kidney Int 2002; 61: 1086-1097.

66. Ruggenenti P, Remuzzi G, on behalf of the Bergamo Dia- 
betic Nephrologic Study Group: Primary prevention of renal failure in diabetic patients: the Bergamo Nephrologic Diabetes Complications Trial. J Hypertens 1998; 16: S95S97.

67. Ruggenenti P, Fassi A, Parvanova Ilieva A, et al: Preventing microalbuminuria in type 2 diabetes. $N$ Engl $\mathrm{J} \mathrm{Med}$ 2004; 351: 1941-1951.

68. Mogensen CE, Neldam S, Tikkanen I, et al: Randomised controlled trial of dual blockade of renin-angiotensin system in patients with hypertension, microalbuminuria, and non-insulin dependent diabetes: the candesartan and lisinopril microalbuminuria study (CALM) study. BMJ 2000; 321: 1440-1444.

69. Parving HH, Lehnert H, Bröchner-Mortensen J, et al: The effect of irbesartan on the development of diabetic nephropathy in patients with type 2 diabetes. $N$ Engl J Med 2001; 345: 870-878.

70. Levey AS, Greene T, Schluchter MD, et al: Glomerular filtration rate measurements in clinical trials. J Am Soc Nephrol 1993; 4: 1159-1171.

71. Brenner BM, Cooper ME, de Zeeuw D, et al: Effects of losartan on renal and cardiovascular outcomes in patients with type 2 diabetes and nephropathy. N Engl J Med 2001; 345: 861-869.

72. Lewis EJ, Hunsicker LG, Bain RP, Rohde RD, for the Collaborative Study Group: The effect of angiotensin-converting enzyme inhibition on diabetic nephropathy. $N$ Engl $J$ Med 1993; 329: 1456-1462.

73. Hansson L, Hedner T, Lindholm L, et al: The Captopril Prevention Project (CAPPP) in hypertension-baseline data and current status. Blood Press 1997; 6: 365-367.

74. Mancia G, Brown M, Castaigne A, et al: Outcomes with nifedipine GITS or co-amilozide in hypertensive diabetics and nondiabetics in Intervention as a Goal in Hypertension (INSIGHT). Hypertension 2003; 41: 431-436.

75. UK Prospective Diabetes Study Group: Tight blood pressure control and risk of macrovascular and microvascular complications in type 2 diabetes: UKPDS 38. BMJ 1998; 317: 703-713.

76. Hansson L, Zanchetti A, Carruthers SG, et al: Effects of intensive blood pressure lowering and low-dose aspirin in patients with hypertension: principal results of the Hypertension Optimal Treatment (HOT) randomised trial. Lancet 1998; 351: 1755-1762.

77. SHEP Cooperative Research Group: Prevention of stroke by antihypertensive drug treatment in older persons with isolated systolic hypertension. Final results of the Systolic Hypertension in the Elderly Program (SHEP). JAMA 1991; 265: 3255-3264.

78. Curb JD, Pressel SL, Cutler JA, et al: Effect of diureticbased antihypertensive treatment on cardiovascular disease risk in older diabetic patients with isolated systolic hypertension. JAMA 1996; 276: 1886-1892.

79. Liu L, Wang JG, Gong L, Liu G, Staessen JA, for the Systolic Hypertension in China (Syst-China) Collaborative Group: Comparison of active treatment and placebo in older patients with isolated systolic hypertension. $J$ Hypertens 1998; 16: 1823-1829.

80. Wang JG, Staessen JA, Gong L, Liu L, for the Systolic Hypertension in China (Syst-China) Collaborative Group:
Chinese trial on isolated systolic hypertension in the elderly. Arch Intern Med 2000; 160: 211-220.

81. Staessen JA, Fagard R, Thijs L, et al: Randomised doubleblind comparison of placebo and active treatment for older patients with isolated systolic hypertension. Lancet 1997; 350: 757-764 (erratum published in Lancet 1997; 350: 1636).

82. Tuomilehto J, Rastenyte D, Birkenhäger WH, et al: Effects of calcium-channel blockade in older patients with diabetes and systolic hypertension. N Engl J Med 1999; 340: 677684.

83. Staessen JA, Thijs L, Birkenhäger WH, Bulpitt CJ, Fagard $\mathrm{R}$, on behalf of the Syst-Eur Investigators: Update on the Systolic Hypertension in Europe (Syst-Eur) Trial. Hypertension 1999; 33: 1476-1477.

84. PATS Collaborative Group: Post-stroke antihypertensive treatment study. A preliminary result. Chin Med J 1995; 108: $710-717$.

85. PROGRESS Management Committee: PROGRESS-Perindopril Protection against Recurrent Stroke Study: characteristics of the study population at baseline. J Hypertens 1999; 17: 1647-1655.

86. Coope J, Warrender TS: Randomised trial of treatment of hypertension in elderly patients in primary care. BMJ 1986 ; 293: 1145-1151.

87. Management Committee: The Australian Therapeutic Trial in Mild Hypertension. Lancet 1980; i: 1261-1267.

88. Amery A, Birkenhäger W, Brixko $\mathrm{P}$, et al: Mortality and morbidity results from the European Working Party on High Blood Pressure in the Elderly trial. Lancet 1985; i: 1349-1354.

89. European Working Party on High Blood Pressure in the Elderly (EWPHE): An international trial of antihypertensive therapy in elderly patients. Objectives, protocol and organization. Arch Intern Pharmacodyn Ther 1985; 275: 300-334.

90. Hypertension-Stroke Cooperative Study Group: Effect of antihypertensive treatment on stroke recurrence. JAMA 1974; 229: 409-418.

91. Medical Research Council Working Party: MRC trial of treatment of mild hypertension: principal results. $B M J$ 1985; 291: 97-104.

92. MRC Working Party: Medical Research Council trial of treatment of hypertension in older adults: principal results. BMJ 1992; 304: 405-412.

93. Dahlöf B, Lindholm LH, Hansson L, Scherstén B, Ekbom T, Wester PO: Morbidity and mortality in the Swedish Trial in Old Patients with Hypertension (STOP-Hypertension). Lancet 1991; 338: 1281-1285.

94. Gong L, Zhang W, Zhu Y, et al: Shanghai trial of nifedipine in the elderly (STONE). J Hypertens 1996; 14: 1237-1245.

95. US Public Health Service Hospitals Cooperative Study Group (McFate Smith WM): Treatment of mild hypertension: results of a ten-year intervention trial. Circ Res 1977; 40: I-98-I-105.

96. Veterans Administration Cooperative Study Group on Antihypertensive Agents: Effect of treatment on morbidity in hypertension: results in patients with diastolic blood pressure averaging 115-129 mmHg. JAMA 1967; 202: 116122. 
97. Kuramoto K, Matsushita S, Kuwajima I, Murakami M: Prospective study on the treatment of mild hypertension in the aged. Jpn Heart J 1981; 22: 75-85.

98. Wolff FW, Lindeman RD: Effects of treatment in hypertension: results of a controlled study. J Chron Dis 1966; 19: 227-240.

99. Carter AB: Hypotensive therapy in stroke survivors. Lancet 1970; 1: 485-489.

100. Veterans Administration-NHLBI Study Group for Cooperative Studies on Antihypertensive Therapy: Mild Hypertension (Perry HM Jr): Treatment of mild hypertension: preliminary results of a two-year feasibility trial. Circ Res 1977; 40: I-180-I-187.

101. Veterans Administration Cooperative Study Group on Antihypertensive Agents: Effects of treatment on morbidity in hypertension II. Results in patients with diastolic blood pressure averaging 90 through $114 \mathrm{mmHg}$. JAMA 1970; 213: 1143-1152.

102. Hypertension Detection and Follow-Up Program Cooperative Group: Five-year findings of the Hypertension Detection and Follow-Up Program. I. Reduction in mortality of persons with high blood pressure, including mild hypertension. JAMA 1979; 242: 2562-2571.

103. Hypertension Detection and Follow-Up Program Cooperative Group: Five-year findings of the Hypertension Detection and Follow-Up Program. III. Reduction in stroke incidence among persons with high blood pressure. JAMA 1982; 247: 633-638.

104. Casiglia E, Spolaore P, Mazza A, et al: Effect of 2 different therapeutic approaches on total and cardiovascular mortality in a cardiovascular study in the elderly. Jpn Heart $J$ 1994; 35: 589-600.

105. Staessen JA, Wang JG: Blood-pressure lowering for the secondary prevention of stroke. Lancet 2001; 358: 10261027.

106. Dahlöf B, Devereux R, de Faire U, et al: The Losartan Intervention For Endpoint reduction (LIFE) in hypertension study: rationale, design and methods. Am J Hypertens 1997; 10: $705-713$.

107. Lindholm LH, Ibsen H, Borch-Johnsen K, et al: Risk of new-onset diabetes in the Losartan Intervention For Endpoint reduction in hypertension study. J Hypertens 2002; 20: $1879-1886$.

108. Hansson L, Lithell H, Skoog I, et al: Study on COgnition and Prognosis in the Elderly (SCOPE). Blood Press 1999; 8: $177-183$.

109. Lithell H, Hansson L, Skoog I, et al: The Study on COgnition and Prognosis in the Elderly (SCOPE): outcomes in patients not receiving add-on therapy after randomisation. $J$ Hypertens 2004; 22: 1605-1612.

110. Wright JT, Kusek JW, Toto RD, et al: Design and baseline characteristics of participants in the African American Study of Kidney disease and hypertension (AASK) pilot study. Control Clin Trials 1996; 16: 3S-16S.

111. World Health Organization-International Society of Hypertension Blood Pressure Lowering Treatment Trialists' Collaboration: Protocol for prospective collaborative overviews of major randomized trials of blood-pressure-lowering treatments. J Hypertens 1998; 16: 127-137.

112. Blood Pressure Lowering Treatment Trialists' Collabora- tion: Effects of ACE inhibitors, calcium antagonists, and other blood pressure-lowering drugs: results of prospectively designed overviews of randomised trials. Lancet 2000; 355: 1955-1964.

113. Blood Pressure Lowering Treatment Trialists' Collaboration: Effects of different blood-pressure-lowering regimens on major cardiovascular events: results of prospectivelydesigned overviews of randomised trials. Lancet 2003; 362: 1527-1535.

114. Wright JT Jr, Agodoa L, Contreras G, et al: Successful blood pressure control in the African American Study of Kidney Disease and Hypertension. Arch Intern Med 2002; 162: 1636-1643.

115. Reugg UT, Wallnofer A, Weir S, Cauvin C: Receptor-operated calcium-permeable channels in vascular smooth muscle. J Cardiovasc Pharmacol 1989; 14 (Suppl 6): S49-S58.

116. Eriksson S, Olofsson BO, Wester PO, for the TEST Study Group: Atenolol in the secondary prevention of stroke. Cerebrovasc Dis 1995; 5: 21-25.

117. Bronner LL, Kanter DS, Manson JE: Primary prevention of stroke. N Engl J Med 1995; 333: 1392-1400.

118. Management Committee on behalf of the High Blood Pressure Research Council of Australia: Australian comparative outcome trial of angiotensin-converting enzyme inhibitorand diuretic-based treatment of hypertension in the elderly (ANBP2): objectives and protocol. Clin Exp Pharmacol Physiol 1997; 24: 188-192.

119. Yui Y, Sumiyoshi T, Kodama K, et al: Comparison of nifedipine retard with angiotensin converting enzyme inhibitors in Japanese hypertensive patients with coronary heart disease: the Japan multicenter investigation for cardiovascular diseases-B (JMIC-B) randomized trial. Hypertens Res 2004; 27: 181-191.

120. Sever PS, Dahlöf B, Poulter NR, et al: Rationale, design, methods and baseline demography of participants of the Anglo-Scandinavian Cardiac Outcomes Trial. J Hypertens 2001; 19: 1139-1147.

121. Sever PS, Dahlöf B, Poulter NR, et al: Prevention of coronary and stroke events with atorvastatin in hypertensive patients who have average or lower-than-average cholesterol concentrations, in the Anglo-Scandinavian Cardiac Outcomes Trial—Lipid Lowering Arm (ASCOTT-LLA): a multicentre randomised controlled trial. Lancet 2003; 361: $1149-1158$.

122. Rousseau MF, Melin J, Benedict CR, et al: Effects of nisoldipine therapy on myocardial perfusion and neuro-humoral status in patients with severe ischaemic left ventricular dysfunction. Eur Heart J 1994; 15: 957-964.

123. Thrackray S, Witte K, Clark AL, Cleland JGF: Clinical trials update: OPTIME-CHF, PRAISE-2, ALLHAT. Eur $J$ Heart Failure 2000; 2: 209-212.

124. Packer M, O'Connor CM, Ghali JK, et al: Effect of amlodipine on morbidity and mortality in severe chronic heart failure. N Engl J Med 1996; 335: 1107-1114.

125. Figulla HR, Gietzen F, Zeymer U, et al: Diltiazem improves cardiac function and exercise capacity in patients with idiopathic dilated cardiomyopathy. Results of the Diltiazem in Dilated Cardiomyopathy Trial. Circulation 1996; 94: 346352.

126. The Danish Study Group on Verapamil in Myocardial Inf- 
arction: Secondary prevention with verapamil after myocardial infarction. Am J Cardiol 1990; 66: 33I-40I.

127. Cleland JGF, Swedberg K, Poole-Wilson PA: Successes and failures in current treatment of heart failure. Lancet 1998; 652 (Suppl 1): 9-28.

128. Yusuf S, Pfeffer MA, Swedberg K, et al: Effects of candesartan in patients with chronic heart failure and preserved left-ventricular systolic function: the CHARM-Alternative trial. Lancet 2003; 362: 777-781.

129. Granger CB, McMurray JJV, Yusuf S, et al: Effects of candesartan in patients with chronic heart failure and reduced left-ventricular systolic function intolerant to angiotensinconverting-enzyme inhibitors: the CHARM-Alternative trial. Lancet 2003; 362: 772-776.

130. McMurray JJV, Östergren J, Swedberg K, et al: Effects of candesartan in patients with chronic heart failure and reduced left-ventricular systolic function taking angiotensin-converting-enzyme inhibitors: the CHARM-Added trial. Lancet 2003; 362: 767-771.

131. White HD: Should all patients with coronary heart disease receive angiotensin-converting-enzyme inhibitors? Lancet 2003; 362: 755-757.

132. Pitt B, Poole-Wilson PA, Segal R, et al: Effect of losartan compared with captopril on mortality in patients with symptomatic heart failure: randomised trial. The Losartan Heart Failure Survival Study ELITE II. Lancet 2000; 355: 15821587.

133. Dickstein K, Kjekshus J, the OPTIMAAL Steering Committee, for the OPTIMAAL Study Group: Effects of losartan and captopril on mortality and morbidity in high-risk patients after acute myocardial infarction: the OPTIMAAL randomised trial. Lancet 2002; 360: 752-760.

134. Cohn JN, Tognoni G, for the Valsartan Heart Failure Trial Investigators: A randomized trial of the angiotensin-receptor blocker valsartan in chronic heart failure. $N$ Engl J Med 2001; 345: 1667-1675.

135. Pfeffer MA, McMurray JJV, Velazquez EJ, et al: Valsartan, captopril, or both in myocardial infarction complicated by heart failure, left ventricular dysfunction, or both. $N$ Engl $J$ Med 2003; 349: 1893-1906.

136. Packer M, Meller J, Gorlin R, Herman MV: Hemodynamic and clinical tachyphylaxis to prazosin-mediated after load reduction in severe chronic congestive heart failure. $\mathrm{Circu}$ lation 1979; 59: 531-539.

137. Lund-Johansen P: Intensive blood pressure lowering treatment: beneficial for all but the smoking hypertensives? $J$ Hypertens 2003; 21: 697-700.

138. Black HR, Elliott WJ, Neaton JD, et al: Rationale and design for the controlled onset verapamil investigation of cardiovascular endpoints (CONVINCE) trial. Control Clin Trials 1998; 19: 370-390.

139. Staessen J, Amery A, Fagard R: Editorial review. Isolated systolic hypertension in the elderly. $J$ Hypertens $1990 ; \mathbf{8}$ : 393-405.

140. Franklin SS, Larson MG, Khan SA, et al: Does the relation of blood pressure to coronary heart disease change with aging? The Framingham Heart Study. Circulation 2001; 103: $1245-1249$.
141. ACE Inhibitor Myocardial Infarction Collaborative Group: Indications for ACE inhibitors in the early treatment of acute myocardial infarction. Systematic overview of individual patient data in randomized trials. Circulation 1998; 97: 2202-2212.

142. Borghi C, Bacchelli S, Degli Esposti D, et al: Effects of the administration of an angiotensin-converting enzyme inhibitor during the acute phase of myocardial infarction in patients with arterial hypertension. Am J Hypertens 1999; 12: $665-672$.

143. Materson BJ, Reda DJ, Cushman WC, et al: Single-drug therapy for hypertension in men. A comparison of six antihypertensive agents with placebo. N Engl J Med 1993; 328: 914-921.

144. Sareli P, Radevski IV, Valtchanova ZP, et al: Efficacy of different drug classes used to initiate antihypertensive treatment in black subjects. Results of a randomized trial in Johannesburg, South Africa. Arch Intern Med 2001; 161: 965-971.

145. Dickerson JEC, Hingorani AD, Ashby MJ, Palmer CR, Brown MJ: Optimisation of antihypertensive treatment by crossover rotation of four major drug classes. Lancet 1999; 353: 2008-2013.

146. Brown MJ, Cruickshank JM, Dominiczak AF, et al: Better blood pressure control: how to combine drugs? J Hum Hypertens 2003; 17: 81-86.

147. Adrougué HJ, Wilson H, Boyd AE, Suki WN, Eknoyan G: Plasma acid-base patterns in diabetic ketoacidosis. $N$ Engl $J$ Med 1982; 307: 1603-1610.

148. Staessen JA, Wang JG, Birkenhäger WH: Outcome beyond blood pressure control? Eur Heart J 2003; 24: 504-514.

149. Dalmay F, Mazouz H, Allard J, Pesteil F, Achard JM, Fournier JM: Non-AT ${ }_{1}$-receptor mediated protective effect of angiotensin against acute ischaemic stroke in the gerbil. $J$ Renin Angiotensin Aldosterone Syst 2001; 2: 103-106.

150. Celentano A, Palmieri V, Di Palma Esposito N, et al: Relations of pulse pressure and other components of blood pressure to preclinical echocardiographic abnormalities. $J$ Hypertens 2002; 20: 531-537.

151. de Simone G, Palmieri V, Bella JN, et al: Association of left ventricular hypertrophy with metabolic risk factors: the HyperGEN study. J Hypertens 2002; 20: 323-331.

152. Rothwell PM: External validity of randomised controlled trials: "to whom do the results of the trial apply?" Lancet 2005; 365: 82-93.

153. Staessen JA, Thijs L, Fagard R, et al: Effects of immediate versus delayed antihypertensive therapy on outcome in the Systolic Hypertension in Europe Trial. J Hypertens 2004; 22: $847-857$.

154. Mancia G, Bombelli M, Lanzarotti A, et al: Systolic vs diastolic blood pressure control in the hypertensive patients of the PAMELA population. Pressioni Arteriose Monitorate E Loro Associazioni. Arch Intern Med 2002; 162: 582-586.

155. Fagard RH, Van den Enden M: Treatment and blood pressure control in isolated systolic hypertension vs diastolic hypertension in primary care. J Hum Hypertens 2003; 17: 681-687. 